\title{
Recent Applications of Magnetic Nanoparticles in Food Analysis
}

\author{
Bárbara Socas-Rodríguez ${ }^{1, *}$, Antonio V. Herrera-Herrera ${ }^{2} \mathbb{D}$, María Asensio-Ramos ${ }^{3}$ and \\ Miguel Ángel Rodríguez-Delgado ${ }^{4}$ \\ 1 Laboratory of Foodomics, Institute of Food Science Research (CIAL), Spanish National Research \\ Council (CSIC), Calle Nicolás Cabrera, 9, 28049 Madrid, Spain \\ 2 Instituto Universitario de Bio-Orgánica Antonio González. Universidad de La Laguna (ULL), \\ Avda. Astrofísico Francisco Sánchez, 2, 38206 San Cristóbal de La Laguna (Tenerife), Spain; \\ avherrer@ull.edu.es \\ 3 Instituto Volcanológico de Canarias (INVOLCAN), 38320 La Laguna (Tenerife), Spain; \\ maria.asensio@involcan.org \\ 4 Departamento de Química, Unidad Departamental de Química Analítica, Facultad de Ciencias, \\ Universidad de La Laguna (ULL), Avda. Astrofísico Francisco Sánchez, s/n, \\ 38206 San Cristóbal de La Laguna (Tenerife), Spain; mrguez@ull.edu.es \\ * Correspondence: barbara.socas@csic.es; Tel.: +34-91-0017-900 (ext. 821)
}

Received: 4 August 2020; Accepted: 7 September 2020; Published: 12 September 2020

\begin{abstract}
Nanotechnology has become a topic of interest due to the outstanding advantages that the use of nanomaterials offers in many fields. Among them, magnetic nanoparticles (m-NPs) have been one of the most widely applied in recent years. In addition to the unique features of nanomaterials in general, which exclusively appear at nanoscale, these present magnetic or paramagnetic properties that result of great interest in many applications. In particular, in the area of food analysis, the use of these nanomaterials has undergone a considerable increase since they can be easily separated from the matrix in sorbent-based extractions, providing a considerable simplification of the procedures. This allows reducing cost and giving fast responses, which is essential in the food trade to guarantee consumer safety. These materials can also be easily tunable, providing higher selectivity. Moreover, their particular electrical, thermal and optical characteristics allow enhancing sensor signals, increasing the sensitivity of the approaches based on this type of device. The aim of this review article is to summarise the most remarkable applications of m-NPs in food analysis in the last five years (2016-2020) showing a general view of the use of such materials in the field.
\end{abstract}

Keywords: food analysis; magnetic nanoparticles; nanomaterials; sample preparation; sensors; sorbent-based extraction

\section{Introduction}

The increasing concern of the global population about food products, their quality, composition and effect on health, as well as the globalisation of the food trade, make necessary the development of reliable strategies that allow food companies to ensure accurate knowledge about their products. This aspect not only involves the evaluation of ingredients and main components, but also those that are present at very low concentration levels and still have a negative effect on consumers such as organic pollutants and microorganisms that endanger food safety [1-3] Therefore, the evaluation of novel analytical methods that lead to these requirements has become an issue of remarkable importance for the scientific community.

The assessment of food products is a complex challenge due to the complexity of these kinds of matrices and the low concentrations at which contaminants can be harmful for consumers. In this 
regard, the development of very sensitive, rapid and selective methodologies results essential and the use of nanomaterials is a cornerstone to achieve these goals [4]. In recent years, nanotechnology has played an important role in many areas, including food analysis as it has been shown in many reports in the literature [1,4-7]. Particular attention has been paid to the use of nanoparticles (NPs) and, especially, in magnetic-NPs (m-NPs) [1,8].

These materials present a small size, from 1 to $100 \mathrm{~nm}$, which gives them great surface area that is excellent for their use in analytical methods. Only a very low amount of material is required in microextractions to reach the same efficiency as in conventional procedures. This definitely constitutes an aspect of great relevance in the current trends based on the principles of sustainable and green chemistry [1]. Apart from that, m-NPs are characterised by other particular features such as high electrical conductivity, coercivity, high magnetic susceptibility and, especially, superparamagnetism that favour their separation from the samples, simplifying the procedures, shortening times and, consequently, reducing costs [1,9]. These characteristics make them ideal for the preparation of sorbents in microextraction techniques or for clean-up steps $[8,10,11]$ and as materials for the preparation of sensors $[1,10,12]$. In this respect, their use in magnetic-micro-dispersive solid-phase extraction (m- $\mu$-dSPE) has constituted their main application, while their utilisation in optical and electrochemical sensors has involved the main uses in these approaches, although other novel systems have also been described in the literature.

There are several types of m-NPs, including alloys and oxides involving both iron and cobalt, fundamentally (i.e., $\mathrm{FePt}, \mathrm{CoPt}_{3}, \mathrm{Fe}_{3} \mathrm{O}_{4}, \mathrm{Fe}_{2} \mathrm{O}_{3}, \mathrm{CoFe}_{2} \mathrm{O}_{4}$, etc.). However, the most widely applied so far have been magnetite $\left(\mathrm{Fe}_{3} \mathrm{O}_{4}\right)$ based NPs $[9,12]$. For their preparation, a great variety of procedures, such as co-precipitation, thermal decomposition, micro-emulsion, or hydrothermal synthesis, has been applied. Moreover, diverse techniques have been used to confirm their structures and assure their suitability for the required applications, including transmission electron microscopy (TEM), X-ray powder diffraction (XRD), Fourier-transform infrared spectroscopy (FTIR) and infrared spectroscopy (IR), vibrating-sample magnetometry (VSM), scanning electron microscopy (SEM) or thermal gravimetric analysis (TGA), among others [8,9].

Despite the unique features of m-NPs that favour their application in the area of food analysis, they have hardly been used without further modifications $[13,14]$. Their combination with other materials has been carried out in most of cases in order to overcome the ease with which they can be oxidised and their trend to aggregation [15]. In fact, to the best of our knowledge, modified m-NPs have been used in all works published in the last five years in sample preparation, and the use of non-modified m-NPs only has been reported for the preparation of sensors used for the evaluation of inorganic compounds [16]. Besides, such combinations aso allow increasing their selectivity of the sorbents and the number of active points on the surface or enhancing electrical and optical properties in sensors $[1,4,5]$. In this respect, they have been combined with polymers or specific molecularly imprinted polymers (MIPs), with different types of aptamers (Apts) and antibodies (Abs), especially in sensor applications, or even with one or more nanomaterials including metal-organic frameworks (MOFs), carbon based nanomaterials and other types of NPs.

The aim of this review article is to compile the most widespread applications of m-NPs in the field of food analysis over the last five years (2016-2020), describing the most relevant uses as sorbents for miniaturised extraction techniques, as well as their use for the preparation and application of sensors. A critical discussion of the main advantages and disadvantages of their use will be presented and the most promising approaches and current trends in the area will be pointed out in order to give the reader a general overview of this issue. 


\section{Recent Applications in Food Analysis}

\subsection{Recent Applications in Sample Preparation}

\subsubsection{Combined with Carbonaceous Nanomaterials}

Carbonaceous nanomaterials have been one the most widely applied sorbent materials in analytical chemistry due to their unique properties provided by the particular arrangement of carbon atoms disposed in planar sheets. A great number of frameworks based on this basic structure exists, including fullerenes, carbon nanotubes (CNTs), graphene, nanodiamonds (NDs), nanofibers (NFs), nanohorns (NHs), etc. All of them present good chemical and thermal stability, as well as mechanical strength, variable electrical conductivity, larger specific surface area and a great capacity to establish $\pi-\pi$ interactions $[5,6,17]$. For these reasons the combination of the advantages brought by these materials with those associated with m-NPs, constitutes a good strategy widely used in sample preparation in the area of food analysis as can be seen in Table 1, in which some of the most recently applications in this field have been compiled [18-27].

Most of the works reported are focused on the combination of iron oxide NPs together with CNTs and their different versions and functionalised forms [19,21-23,28], as well as graphene and modified graphene [20,24,27]. However, graphitized carbon black (GCB) has also been applied [26], along with ternary composites using NDs [18], and other non-carbonaceous nanomaterials. They have been used for the analysis of organic compounds in milk $[18,19,26,27]$, fruit $[18,29]$, oil [24], meat [18] or cereal based products [20,22], among others such as beverages, eggs, cacao, honey and coffee.

Although in most cases these sorbents are used as extraction materials, their application as clean-up sorbents has also been carried out showing a clear reduction of the matrix effect. As an example, Ma et al. [22] used a combination of $\mathrm{Fe}_{3} \mathrm{O}_{4}$ and multi-walled CNTs (MWCNTs) for the clean-up step of the QuEChERS (quick, easy, cheap, effective, rugged, safe) renowned method applied for the extraction of 20 mycotoxins from rice, millet, wheat, corn and coix seed prior to determination by ultra-high performance liquid chromatography-tandem mass spectrometry (UHPLC-MS/MS). Apart from reducing the pre-treatment time as a consequence of using a magnetic sorbent easily removed by an external magnet, the whole methodology showed very good sensitivity with limits of detection (LODs) in the range $0.0006-1.6337 \mu \mathrm{g} / \mathrm{kg}$ and an extraction efficiency similar or even better than for other sorbents commonly used in this technique such as octadecylsilane $\left(\mathrm{C}_{18}\right)$, primary-secondary amine (PSA) and GCB, with recovery values between $70 \%$ and $113 \%$.

Despite the fact that the introduction of carbonaceous materials already increases the possibility of establishing interactions with the target analytes, favouring the extraction efficiency; in some cases, further functionalisation with specific groups could considerably improve the selectivity of the procedure as was demonstrated by Fu et al. [19]. In this work, authors compared the extraction rate of 13 sulfonamides from milk samples using MWCNTs and those modified with $\mathrm{C}_{18}$ and p-Tolyl isocyanates (Tol). Results showed that the inclusion of those moieties on the surface of the sorbent clearly improved the extraction efficiency of the applied vortex assisted-magnetic-micro-dispersive solid-phase extraction (VA-m- $\mu$-dSPE) method. Moreover, as the absorption percentage was slightly higher with Tol-MWCNTs for most of the target analytes, this modified sorbent was used for the validation of the methodology using high-performance liquid chromatography-mass spectrometry (HPLC-MS) as the determination technique. Results showed good sensitivity with LODs of 2-10 ng/L and adequate recovery values in the range $81-109 \%$. However, authors noticed that the hydrophobic interactions established by Tol moieties hindered the correct removal of some interferences with similar nature as the target analytes. 
Table 1. Recent applications of magnetic carbonaceous nanomaterials as extraction sorbents in food analysis.

\begin{tabular}{|c|c|c|c|c|c|c|c|}
\hline Analytes & Matrix & Nanomaterial & Extraction Technique & $\begin{array}{l}\text { Determination } \\
\text { Technique }\end{array}$ & $\begin{array}{c}\text { Recovery } \\
\%\end{array}$ & LOD & Reference \\
\hline Vitamin $B_{12}$ & $\begin{array}{l}\text { Milk-based infant } \\
\text { formula, orange } \\
\text { and peach juice, } \\
\text { meat, salami, } \\
\text { powder milk } \\
(2 \mathrm{~mL} \text { extract })\end{array}$ & $\begin{array}{c}\mathrm{Fe}_{3} \mathrm{O}_{4} @ \mathrm{MWCNTs} @ \mathrm{NDs} \\
(50 \mathrm{mg})\end{array}$ & $\mathrm{m}-\mu-\mathrm{dSPE}$ & HPLC-DAD & $>98$ & $2.85 \mu \mathrm{g} / \mathrm{L}$ & [18] \\
\hline 13 Sulfonamides & $\begin{array}{c}\text { Milk } \\
(30 \mathrm{~mL}) \\
\end{array}$ & $\begin{array}{c}\mathrm{Fe}_{3} \mathrm{O}_{4} @ \mathrm{MWCNTs} \text {-p-tolyl } \\
(40 \mathrm{mg})\end{array}$ & VA-m- $\mu-d S P E$ & HPLC-(Q-OrbiTrap)-MS & 81-109 & $2-10 \mathrm{ng} / \mathrm{L}$ & [19] \\
\hline 4 Aflatoxins & $\begin{array}{l}\text { White and moldy } \\
\text { bread } \\
(20 \mathrm{mg})\end{array}$ & $\begin{array}{c}\mathrm{Fe}_{3} \mathrm{O}_{4} @ 3 \text { Dgraphene } \\
\text { (20 mg) }\end{array}$ & In-syringe-m- $\mu$-dSPE & HPLC-FD & $59-69$ & $0.06-0.1 \mu \mathrm{g} / \mathrm{kg}$ & [20] \\
\hline 6 PAEs & $\begin{array}{l}\text { Carbonated soft } \\
\text { drinks } \\
(-)\end{array}$ & $\begin{array}{l}\text { MWCNT- } \mathrm{Fe}_{3} \mathrm{O}_{4} / \mathrm{AgNPs} \\
(10 \mathrm{mg})\end{array}$ & $\mathrm{m}-\mu-\mathrm{dSPE}$ & GC-(Q)-MS & 97-109 & $10.8-22.5 \mathrm{ng} / \mathrm{L}$ & [21] \\
\hline 20 Mycotoxins & $\begin{array}{l}\text { Rice, millet, wheat, } \\
\text { corn, coix seed } \\
(5 \mathrm{~g})\end{array}$ & $\begin{array}{l}\mathrm{Fe}_{3} \mathrm{O}_{4} @ \mathrm{MWCNT} \\
(20 \mathrm{mg})\end{array}$ & QuEChERS & UHPLC-(QqQ)-MS/MS & $74-113$ & $0.0006-1.6337 \mu \mathrm{g} / \mathrm{kg}$ & [22] \\
\hline $\begin{array}{l}6 \text { Sudan dye, } \\
\text { Para Red }\end{array}$ & $\begin{array}{l}\text { Chili powder, chili } \\
\text { tomato sauce, } \\
\text { ketchup } \\
(10 \mathrm{~g})\end{array}$ & $\begin{array}{c}\mathrm{Fe}_{2} \mathrm{O}_{3} @ \mathrm{COOH}-\mathrm{MWCNT} \\
(20 \mathrm{mg})\end{array}$ & $\mathrm{m}-\mu-\mathrm{dSPE}$ & HPLC-DAD & - & $0.13-0.84 \mu \mathrm{g} / \mathrm{L}$ & [23] \\
\hline $\begin{array}{l}\text { Sesamol, sesamin, } \\
\text { sesamolin }\end{array}$ & $\begin{array}{l}\text { Sesame oil } \\
\quad(0.1 \mathrm{~g})\end{array}$ & $\begin{array}{l}\mathrm{Fe}_{3} \mathrm{O}_{4} @ \mathrm{GO} \\
(1.4 \mathrm{mg})\end{array}$ & VA-m- $\mu-d S P E$ & HPLC-UV & $85-87$ & $0.02-0.05 \mathrm{mg} / \mathrm{kg}$ & [24] \\
\hline $\begin{array}{l}7 \text { Multiclass } \\
\text { pesticides }\end{array}$ & $\begin{array}{l}\text { Raisin product } \\
\qquad(5 \mathrm{~g})\end{array}$ & $\begin{array}{l}\mathrm{Fe}_{3} \mathrm{O}_{4} @ \mathrm{r}-\mathrm{GO} \\
\quad(10 \mathrm{mg})\end{array}$ & $\mathrm{m}-\mu-\mathrm{dSPE}$ & GC-(Q)-MS & $93-119$ & $14-40 \mu \mathrm{g} / \mathrm{kg}$ & [25] \\
\hline 6 Mycoestrogens & $\begin{array}{l}\text { Cow milk } \\
\quad(8 \mathrm{~mL})\end{array}$ & $\begin{array}{l}\mathrm{Fe}_{3} \mathrm{O}_{4} @ \mathrm{GCB} \\
\quad(100 \mathrm{mg})\end{array}$ & VA-m- $\mu-d S P E$ & UHPLC-(QqQ)-MS/MS & $70-91$ & $3-9 \mathrm{ng} / \mathrm{L}$ & [26] \\
\hline 4 Sulfonamides & $\begin{array}{c}\text { Milk } \\
(1.5 \mathrm{~mL})\end{array}$ & $\begin{array}{c}\mathrm{Fe}_{3} \mathrm{O}_{4} @ \text { graphene } \\
\text { (15 mg) }\end{array}$ & VA-m- $\mu-d S P E$ & CE-DAD & $3-105$ & $0.89-2.31 \mu \mathrm{g} / \mathrm{L}$ & [27] \\
\hline
\end{tabular}

CE: capillary electrophoresis; COOH-MWCNT: carboxylated multi-walled carbon nanotubes; DAD: diode array detector; FD: fluorescence detection; GC: gas chromatography; GCB: graphitized carbon black; GO: graphene oxide; HPLC: high performance liquid chromatography; LOD: limit of detection; m- $\mu$-dSPE: magnetic-micro-dispersive solid-phase extraction; MS: mass spectrometry; MS/MS: tandem mass spectrometry; MWCNT: multi-walled carbon nanotube; ND: nanodiamon; NP: nanoparticle; PAE: phthate ester; Q: single quadrupole; QqQ: triple quadrup of vortex assisted. 
As previously indicated, the combination of m-NPs with more than one type of carbonaceous nanomaterial has also been tested for the evaluation of organic compounds from food matrices in order to improve the extraction performance. In this regard, Ulusoy et al. [18] took advantage of the simultaneous application of two different carbonaceous nanomaterials (MWCNTs and NDs) to prepare a magnetic composite with $\mathrm{Fe}_{3} \mathrm{O}_{4}$ for the extraction of vitamin $\mathrm{B}_{12}$ from milk-based infant formula and cereals prior to its analysis by high performance liquid chromatography-diode array detector (HPLC-DAD). In this case, apart from the advantages related to the combination of MWCNTs with the m-NPs due to the strong van der Waals interactions points provided by this carbon-based nanomaterial, the addition of NDs to the prepared composite also improves its quality. NDs avoid the $\pi-\pi$ interactions between the graphene sheets that constitute the MWCNTs, decreasing the trend to aggregation of this material, which commonly diminishes its surface area and the number of active points that can interact with target analytes. Authors remarked that the particular characteristics of the prepared magnetic nanomaterial lead to a clear improvement in the extraction efficiency of the procedure highlighting the benefits of this new-generation material. This fact allowed the validation of a wide variety of complex food matrices of different nature with very good results, giving rise to a LOD of $2.85 \mu \mathrm{g} / \mathrm{L}$ and recovery values higher than $98 \%$.

Another carbon-based material most commonly combined with m-NPs for the evaluation of food commodities has been graphene [20,27] and its varieties including graphene oxide (GO) [24] or reduced-GO (r-GO) [25]. These materials involve an easier synthesis with lower residues production than CNTs, which has increased their use in this and other related areas [17]. Nevertheless, as with CNTs, the $\pi-\pi$ stacking, hydrophobic interactions and van der Waals forces between sheets lead to the formation of agglomerates that decrease the nanomaterial surface area. In this respect, the combination with NPs, and particularly m-NPs, seems to be a good strategy to avoid these problems $[27,30]$. Additionally, the use of oxide forms also favours such an aspect, increasing the polarity and hydrophilicity of the material with the introduction of hydroxyl, carboxy and epoxy groups on its surface, although the ultra-lightness of GO and r-GO forms also makes very useful their combination with NPs and m-NPs to hinder their aggregation tendency [27]. An interesting application was that developed by Wu et al. [24] who only needed $1.4 \mathrm{mg}$ of $\mathrm{Fe}_{3} \mathrm{O}_{4} @ \mathrm{GO}$ as sorbent to carry out the VA-m- $\mu$-dSPE of sesamol, sesamin and sesamolin from $0.1 \mathrm{~g}$ of sesame oil prior to their separation and analysis by HPLC-ultraviolet (UV) detection. Although the authors used $5.7 \mathrm{~mL}$ of dichloromethane (DCM) for sample solubilisation and matrix clean-up, which reduces the sustainable and green character of the methodology, solvent consumption and sample requirements were demonstrated to be lower than other compared procedures. For example, saponification or solid-phase extraction (SPE) using alumina as sorbent could need up to $160 \mathrm{~mL}$ and $300 \mathrm{~mL}$ of organic solvent and $0.5 \mathrm{~g}$ and $5 \mathrm{~g}$ of sample, respectively. Apart from that, it is worth mentioning that thanks to the use of m-NPs and the ease of removing them from the matrix with the assistance of an external magnet, the pre-treatment step could be time reduced when VA-m- $\mu$-dSPE was employed, obtaining recovery values in the same order or even higher than in the other cases (85-87\%) and very good sensitivity, with LODs in the range $0.02-0.05 \mathrm{mg} / \mathrm{kg}$.

Another strategy also applied in the area of food analysis for m-NPs@graphene sorbents has been the preparation of three-dimensional graphene (3Dgraphene). This approach consists of reassembly the two-dimensional graphene structure in aerogels, sponges or foams in order to favour the separation between sheets, avoiding agglomeration and active surface restrictions. In addition, such modification also leads to lower density, faster mass and electron transport kinetics, as well as to enhanced mechanical strength, as a consequence of the framework and unique properties of graphene [30]. Moreover, the addition of m-NPs to the structure also improves the characteristics of the material favouring the performance of the extraction process and decreasing the complexity as well as time consumption, which also involves a reduction of costs, aspect of great importance for routine procedures in food industry. Another interesting application of 3Dgraphene was carried out by Sereshti et al. [20], who made use of the advantages of m-NPs in a different way than usual in this kind of extraction 
technique for the determination of aflatoxins in bread samples. In this work, the authors placed $20 \mathrm{mg}$ of $\mathrm{Fe}_{3} \mathrm{O}_{4} @ 3$ Dgraphene on a magnet sheet located in a filter holder, as shown in Figure 1. After conditioning the nanomaterial using methanol $(\mathrm{MeOH})$ and water, $50 \mathrm{~mL}$ of an aqueous-organic extract, obtained after ultrasound assisted-solid-liquid extraction of $3 \mathrm{~g}$ of dried bread matrix, were loaded in a syringe and passed through the material magnet filter. By pulling back the plunger, the adsorbent particles were removed from the magnetic sheet and dispersed into the syringe. Then, the plunger was pushed to pass the sample solution through the filter and the analytes were eluted using $700 \mu \mathrm{L}$ of $\mathrm{MeOH}$ and subsequently analysed by HPLC-fluorescence detection (FD). Validation of the methodology led to intermediate recovery values (59-69\%) and good sensitivity with LODs in the range $0.06-0.1 \mu \mathrm{g} / \mathrm{kg}$.

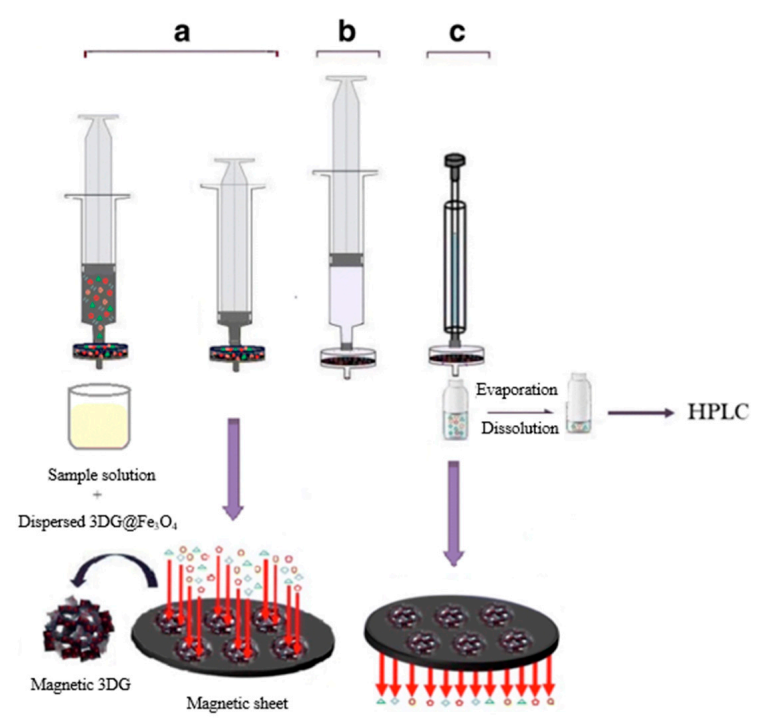

Figure 1. Scheme of an in-syringe- magnetic-micro-dispersive solid-phase extraction (m- $\mu$-dSPE) using $\mathrm{Fe}_{3} \mathrm{O}_{4} @ 3$ graphene as sorbent for the evaluation of aflotoxins in bread samples. (a) Sample loading, (b) washing by distilled water, (c) desorption using $\mathrm{MeOH}$. Reprinted from [20], with permission from Springer, 2020.

Apart from that, the combinations with other materials that provide complementary properties to the magnetic carbonaceous composites have also been evaluated. Among them, combinations of magnetic CNTs, graphene or GO with other non-magnetic NPs, polymers or MOFs have also been carried out. The main objectives in all these studies were to increase the reproducibility, stability and above all, the extraction efficiency and the selectivity of the sorbent. An interesting example is the combination with non-magnetic NPs as carried out Moazzen et al. [21] for the extraction of six phthalic

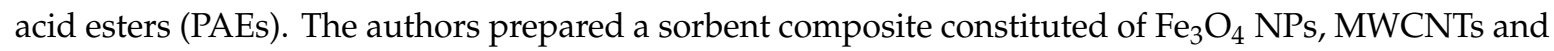
Ag NPs since this last component provides considerable mechanical and thermal strength, catalytic enhancement and increase of the surface area, which enlarge the possibility of interaction with target compounds, accelerating the absorption and desorption processes. The good performance of the extraction process based on the developed $\mathrm{MWCNT}-\mathrm{Fe}_{3} \mathrm{O}_{4} / \mathrm{AgNPs}$ sorbent allows its application in complex carbonated soft drinks using only $10 \mathrm{mg}$, obtaining recovery values in the range $97-109 \%$ and LODs of the method between $10.8 \mathrm{ng} / \mathrm{L}$ and $22.5 \mathrm{ng} / \mathrm{L}$.

As can be seen in all these examples, the combination of m-NPs with carbonaceous nanomaterials not only improves the active interaction sites of the magnetic material, increasing the selectivity and efficiency of the extraction procedure, but also improves the performance of the methodology because of the synergic effect of the advantages provided by both nanostructures. Moreover, in addition to the benefits already described, the possibility of reusing these sorbents should also be highlighted as has been demonstrated in most of the articles compiled in Table 1 . This aspect reinforces the valorisation 
of the new sorbents developed, as well as the methodologies carried out based on their application, especially in the field of food analysis, in which the use of simple, cheap and low cost procedures that allow the producers to guarantee the safety of consumers, is essential for the correct development of market and food industry.

\subsubsection{Combined with Metal-Organic Frameworks}

MOFs are in general composed by a metal ion or a metal cluster centre, self-assembled with a 3D organic ligands framework. They have been extensively used in food analysis in the last decades due to their pore design and functionalisation flexibility and high surface area, as shown in different reviews dealing with the topic $[31,32]$. Their combination with $\mathrm{m}-\mathrm{NPs}$ to form the so-called magnetic MOFs (m-MOFs) or magnetic frameworks composites (m-FCs) provides them in general with a better stability than MOFs alone, as well as superparamagnetism, rapid and easy adsorption/desorption steps and high recycling rates. Table 2 shows a selection of recent applications of $\mathrm{m}-\mathrm{MOF}$ to the food analysis field [33-42]. The works reported describe the extraction of both organic [33,34,36-38,41-43] and inorganic $[39,40]$ compounds in a wide variety of matrices.

There are different techniques to synthesise m-MOFs, i.e., mixing, sealing and surface modification, which gives mixed, embedded and core-shell structures. Each of them shows different advantages and disadvantages already discussed in the literature [44].

The mixing technique is the easiest way to synthesise m-MOFs, since it consists on mixing MOFs with a m-NP precursor. However, co-precipitation makes difficult the control of the structure, and elution is normally difficult. Some examples of m-MOFs synthesised in this way can be found in the food analysis field [33,34]. Durmus et al. [33] proposed a multi-component $\mathrm{Fe}_{3} \mathrm{O}_{4} @ \mathrm{SiO}_{2} @ \mathrm{MIL}-53(\mathrm{Al})$ composite synthesised by co-precipitation of MIL-53(Al) with core-shell $\mathrm{Fe}_{3} \mathrm{O}_{4} @ \mathrm{SiO}_{2}$ m-NPs. $\mathrm{Fe}_{3} \mathrm{O}_{4}$ NPs were first prepared by precipitation using $\mathrm{Fe}(\mathrm{II})$ and $\mathrm{Fe}(\mathrm{III})$, the $\mathrm{Fe}_{3} \mathrm{O}_{4} @ \mathrm{SiO}_{2}$ core-shell NPs were synthesised using the Stöber biphasic method [45] and MIL-53(Al) was commercially purchased. Authors structurally and morphologically characterized $\mathrm{Fe}_{3} \mathrm{O}_{4}, \mathrm{Fe}_{3} \mathrm{O}_{4} @ \mathrm{SiO}_{2}$ and $\mathrm{Fe}_{3} \mathrm{O}_{4} @ \mathrm{SiO}_{2} @ \mathrm{MIL}-53(\mathrm{Al})$. Regarding surface characteristics, $\mathrm{Fe}_{3} \mathrm{O}_{4} @ \mathrm{SiO}_{2} @ \mathrm{MIL}-53(\mathrm{Al})$ exhibited higher surface area and total pore volume than the others, as expected. Ten $\mathrm{mg}$ of this composite was successfully applied to extract aflatoxin $B_{1}$ from $2 \mathrm{~mL}$ of 11 different species extracts using $\mathrm{m}-\mu-\mathrm{dSPE}$, with a LOD of $0.5 \mu \mathrm{g} / \mathrm{L}$ and good recovery values (71-97\%). A mixture of acetone/acetonitrile $(\mathrm{ACN}) / \mathrm{DCM}(1: 1: 2, v / v / v)$ was used as elution solvent and fluorescence spectrophotometry as detection technique. Shi et al. [34] also employed a simple mixing method for the synthesis of $\mathrm{Fe}_{3} \mathrm{O}_{4}-\mathrm{NH}_{2} @$ MIL-101. In this case, amine-functionalised $\mathrm{Fe}_{3} \mathrm{O}_{4}$ particles $\left(\mathrm{Fe}_{3} \mathrm{O}_{4}-\mathrm{NH}_{2}\right)$ were prepared by mixing 1,6-hexanediamine with $\mathrm{FeCl}_{3}$, ethylene glycol (EG) and anhydrous sodium acetate, while MIL-101 was hydrothermally synthesised by mixing $\mathrm{Cr}\left(\mathrm{NO}_{3}\right)_{3} \cdot 9 \mathrm{H}_{2} \mathrm{O}$ with terephthalic acid (BDC). They were later mixed to obtain $\mathrm{Fe}_{3} \mathrm{O}_{4}-\mathrm{NH}_{2} @$ MIL-101. A simple experiment was used to check the adsorption capacity of $\mathrm{Fe}_{3} \mathrm{O}_{4}-\mathrm{NH}_{2} @ \mathrm{MIL}-101$ against $\mathrm{Fe}_{3} \mathrm{O}_{4}-\mathrm{NH}_{2}$, which consisted in dispersing the same amount of each in a Sudan Red 7B solution, showing that, with the help of an external magnet, the $\mathrm{Fe}_{3} \mathrm{O}_{4}-\mathrm{NH}_{2} @$ MIL-101 supernatant became clear while the other did not change colour. This demonstrated the excellent extraction capacity of porous MIL-101. Three mg of this composite was used for the $\mathrm{m}-\mu$-dSPE of 6 Sudan dyes in tomato sauce. The analytes were extracted with $2 \times 5 \mathrm{~mL} A C N$ from $4 \mathrm{~g}$ sample and the extracts were dried and redissolved in $1 \mathrm{~mL}$ of $\mathrm{MeOH} / \mathrm{water}$ which was the liquid phase in the extraction procedure. Ethyl acetate $(2 \times 1 \mathrm{~mL})$ was used as elution solvent, obtaining recovery values in the range 70-93\% and LODs of $0.5-2.5 \mu \mathrm{g} / \mathrm{g}$. Figure 2 shows the typical HPLC-DAD chromatograms of a tomato sauce sample (A), a spiked tomato sauce sample (B) and a spiked tomato sauce sample submitted to the $\mathrm{Fe}_{3} \mathrm{O}_{4}-\mathrm{NH}_{2} @ \mathrm{MIL}-101 \mathrm{~m}-\mu$-dSPE procedure. The authors also compared the synthesised composite with other commercial sorbents- $\mathrm{C}_{18}$, hydrophilic-lipophilic balance (HLB) and alumina- showing higher extraction efficiencies than HLB and alumina and comparable to $C_{18}$. Furthermore, the sorbent demonstrated good performance when reused up to 10 times using a simple reconditioning protocol. 
Table 2. Recent applications of magnetic metal-organic frameworks as extraction sorbents in food analysis.

\begin{tabular}{|c|c|c|c|c|c|c|c|}
\hline Analytes & Matrix & Nanomaterial & Extraction Technique & $\begin{array}{l}\text { Determination } \\
\text { Technique }\end{array}$ & $\begin{array}{c}\text { Recovery } \\
\%\end{array}$ & LOD & Reference \\
\hline Aflatoxin $\mathrm{B}_{1}$ & $\begin{array}{c}\text { Species } \\
(2 \mathrm{~mL} \text { extract })\end{array}$ & $\begin{array}{c}\mathrm{Fe}_{3} \mathrm{O}_{4} @ \mathrm{SiO}_{2} @ \mathrm{MIL}-53(\mathrm{Al}) \\
(100 \mathrm{mg})\end{array}$ & $\mathrm{m}-\mu$-dSPE & FD & $71-97$ & $0.5 \mu \mathrm{g} / \mathrm{L}$ & [33] \\
\hline 6 Sudan dyes & $\begin{array}{l}\text { Tomato sauce } \\
(1 \mathrm{~mL} \text { extract })\end{array}$ & $\begin{array}{c}\mathrm{Fe}_{3} \mathrm{O}_{4}-\mathrm{NH}_{2} @ \mathrm{MIL}-101 \\
(3 \mathrm{mg})\end{array}$ & $\mathrm{m}-\mu$-dSPE & HPLC-DAD & $70-93$ & $0.5-2.5 \mu \mathrm{g} / \mathrm{kg}$ & [34] \\
\hline 2 Pyrethroid pesticides & $\begin{array}{c}\text { Fruit juice } \\
(100 \mathrm{~mL}, 1: 3 v / v \text { aqueous } \\
\text { solution })\end{array}$ & $\mathrm{Fe}_{3} \mathrm{O}_{4} @ \mathrm{MAA} @ \mathrm{TMU}-21$ (4 mg) & $\mathrm{m}-\mu$-dSPE & HPLC-UV & $93-105$ & $0.05-0.1 \mu \mathrm{g} / \mathrm{L}$ & [35] \\
\hline $\begin{array}{c}3 \\
\text { Organophosphoruspesticides }\end{array}$ & $\begin{array}{c}\text { Rice } \\
(25 \mathrm{~mL} \text { extract }) \\
\end{array}$ & $\begin{array}{c}\mathrm{Fe}_{3} \mathrm{O}_{4} @ \mathrm{ThGA} @ \mathrm{TMU}-6 \\
(2 \mathrm{mg})\end{array}$ & $\mathrm{m}-\mu-\mathrm{dSPE}$ & HPLC-UV & $88-107$ & $0.5-1.0 \mu \mathrm{g} / \mathrm{L}$ & [36] \\
\hline 8 Sedative drugs & $\begin{array}{c}\text { Pork meat } \\
(10 \mathrm{~mL} \text { tert-butyl methyl } \\
\text { ether extract })\end{array}$ & $\begin{array}{c}\mathrm{Fe}_{3} \mathrm{O}_{4} @ \mathrm{TbBd} @ \mathrm{ZIF}-8 \\
(7 \mathrm{mg})\end{array}$ & $V A-m-\mu-d S P E$ & HPLC-MS/MS & $73-93$ & $0.04-0.2 \mu \mathrm{g} / \mathrm{kg}$ & {$[37]$} \\
\hline 6 Benzoylurea insecticides & $\begin{array}{c}\text { Tea infusion } \\
(8 \mathrm{~mL})\end{array}$ & $\begin{array}{c}\mathrm{Fe}_{3} \mathrm{O}_{4} @ \text { ATP@ZIF-8 } \\
(30 \mathrm{mg})\end{array}$ & VA-m- $\mu-d S P E$ & HPLC-DAD & $79-114$ & $0.7-3.2 \mu \mathrm{g} / \mathrm{L}$ & {$[38]$} \\
\hline $\mathrm{Hg}(\mathrm{II})$ & $\begin{array}{l}\text { Fish and canned tuna } \\
\text { (100 mL diluted extract) }\end{array}$ & $\begin{array}{c}\mathrm{Fe}_{3} \mathrm{O}_{4} @ \text { DTIM@MOF-199 } \\
(24 \mathrm{mg})\end{array}$ & $\mathrm{m}-\mu$-dSPE & FAAS & 95-102 & $10 \mathrm{ng} / \mathrm{L}$ & [39] \\
\hline $\mathrm{Sn}(\mathrm{II}), \mathrm{Sn}(\mathrm{IV})$ & $\begin{array}{l}\text { Canned tuna fish, canned } \\
\text { cherry, tomato paste } \\
\text { (250 mL diluted extract) }\end{array}$ & $\begin{array}{c}\mathrm{Fe}_{3} \mathrm{O}_{4} @ \mathrm{SiO}_{2} @ \mathrm{PAN} @ \mathrm{MIL}-101(\mathrm{Cr}) \\
(21 \mathrm{mg})\end{array}$ & UA-m- $\mu$-dSPE & ET-AAS & $87-96$ & $5.0 \mathrm{ng} / \mathrm{L}$ & {$[40]$} \\
\hline 4 Triazole fungicides & $\begin{array}{c}\text { Honey, fruit juices } \\
\text { (30 mL diluted extract) }\end{array}$ & $\begin{array}{c}\mathrm{Fe}_{3} \mathrm{O}_{4} @ \text { APTES-GO@ZIF-8 } \\
(16 \mathrm{mg})\end{array}$ & $\mathrm{m}-\mu$-dSPE & HPLC-DAD & $72-111$ & $0.014-0.109 \mu \mathrm{g} / \mathrm{L}$ & [41] \\
\hline 4 Tetracycline antibiotics & $\begin{array}{c}\text { Milk, egg, chicken muscle, } \\
\text { kidney } \\
\text { (10 mL extract) }\end{array}$ & $\begin{array}{c}\mathrm{Fe}_{3} \mathrm{O}_{4} @ \mathrm{MOF}-199 /(\mathrm{EHA} / \mathrm{DVB} / \mathrm{MMA}) \\
\text { polyHIPE } \\
(1.2 \mathrm{~cm} \text { diameter, } 6.0 \mathrm{~mm} \text { thickness })\end{array}$ & m-SCSE & HPLC-FD & $87-111$ & $\begin{array}{c}1.9-13.9 \mu \mathrm{g} / \mathrm{L} \\
\text { (milk and egg); } \\
1.8-13.0 \mu \mathrm{g} / \mathrm{kg} \\
\text { (chicken muscle } \\
\text { and kidney) }\end{array}$ & {$[42]$} \\
\hline
\end{tabular}

APTES: (3-aminopropyl) triethoxysilane; ATP: attapulgite; Bd: bencidine; DAD: diode array detector; DTIM: 4-(5)-imidazoledithiocarboxylic acid; DVB: divinylbenzene; EHA: 2-ethylhexylacrylate; ET-AAS: electrothermal atomic absorption spectroscopy; FAA: flame atomic absorption spectroscopy; FD: fluorescence detection; GO: graphene oxide; HPLC: high performance liquid chromatography; LOD: limit of detection; MAA: methylacrylic acid; m- $\mu$-dSPE: magnetic-micro-dispersive solid-phase extraction; MMA: methyl methacrylate; m-SCSE: magnetic-stir cake sorptive extraction; MS/MS: tandem mass spectrometry; PAN: 1-(2-Pyridylazo)-2-naphthol; polyHIPE: polymerised high internal phase emulsion; Tb:

1,3,5-triformylbenzene; ThGA: thioglycolic acid; UA: ultrasound assisted; UV: ultraviolet; VA: vortex assisted. 


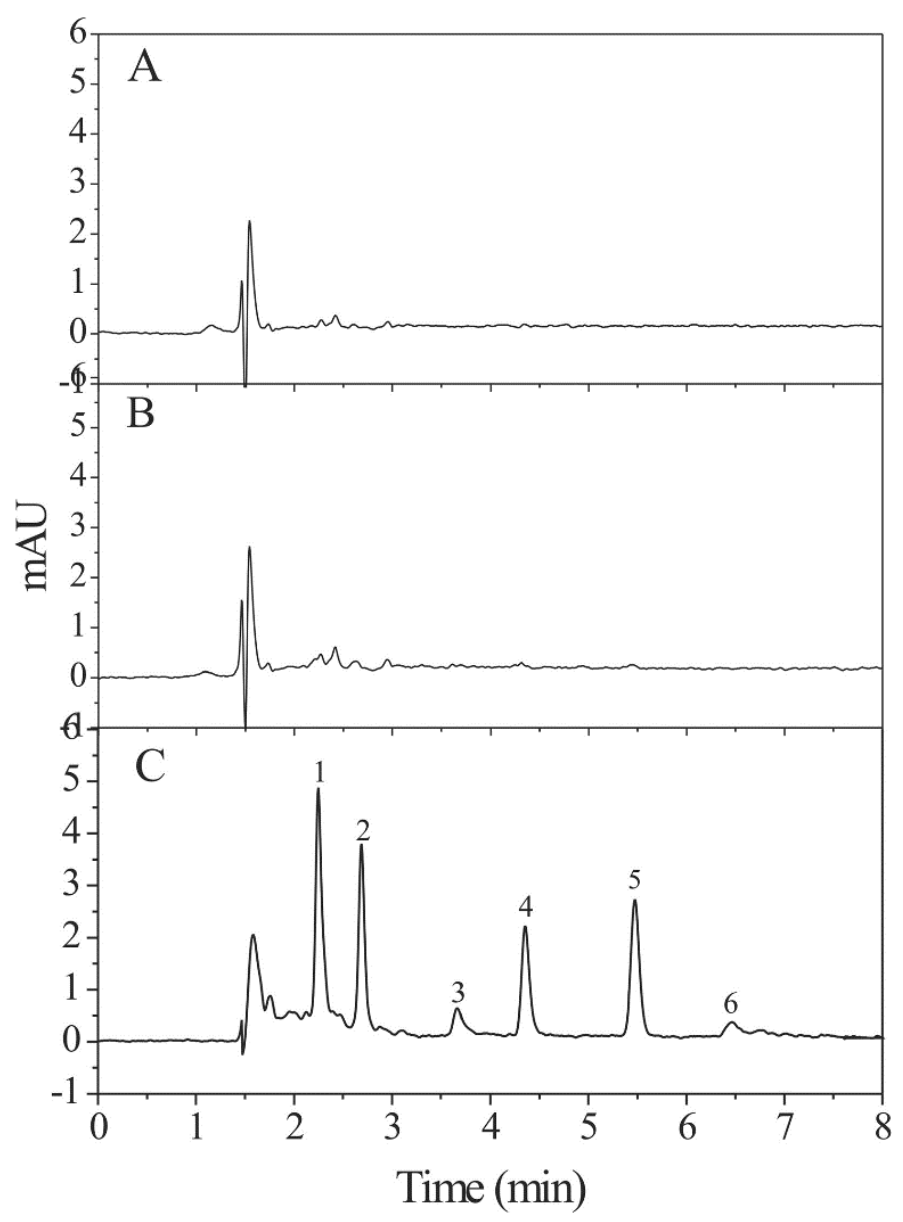

Figure 2. Typical high performance liquid chromatography-diode array detector (HPLC-DAD) chromatograms of a tomato sauce sample (A), a tomato sauce sample, (B) a spiked tomato sauce sample (C) a spiked tomato sauce sample submitted to the $\mathrm{Fe}_{3} \mathrm{O}_{4}-\mathrm{NH}_{2} @ \mathrm{MIL}-101 \mathrm{~m}-\mu$-dSPE procedure. Reprinted from [34] with permission from Elsevier, 2020.

Another way to synthesise m-MOFs is by surface modification [35-37]. In this regard, Yamini et al. [35] employed a layer-by-layer strategy to prepare a TMU-21 based MFC capable of extracting 2 pyrethroid pesticides from fruit juice after a m- $\mu$-SPE-HPLC-UV method. First, $\mathrm{Fe}_{3} \mathrm{O}_{4} \mathrm{NPs}$ were synthesised from $\mathrm{Fe}(\mathrm{II})$ and $\mathrm{Fe}(\mathrm{III})$ by precipitation. Then, bis-pyridin-4-ylmethylene-naphtalene-1,5-diamine (4-nbpy), the principal ligand of TMU-21, was synthesised from 4-pyridinecarboxaldehyde in ethanol (EtOH) and 1,5-diaminonaphtalene after the addition of DCM. The MFCs were assembled by dispersing methylacrylic acid (MAA)-modified $\mathrm{Fe}_{3} \mathrm{O}_{4}\left(\mathrm{Fe}_{3} \mathrm{O}_{4} @ \mathrm{MAA}\right.$ ) with zinc nitrate dimethylformamide (DMF) solution, 4-nbpy and the acidic ligand 4,4'-oxybis(benzoic acid) $\left(\mathrm{H}_{2} \mathrm{oba}\right)$ DMF solution. $\mathrm{Fe}_{3} \mathrm{O}_{4} @ \mathrm{TMU}-21$ sorbent showed excellent water, solvent and thermal stability and combined the magnetic properties of $\mathrm{Fe}_{3} \mathrm{O}_{4}$ with the increase of the surface area provided by TMU-21. Four mg of this nanomaterial was used for the extraction of the analytes from a 1:3 $v / v$ aqueous juice solution, taking advantage of the $\pi-\pi$ stacking, hydrophobic and hydrogen-bond interactions. 1-butanol was used as elution solvent $(80 \mu \mathrm{L})$, providing good results in terms of recovery (93-105\%) and LODs $(0.05-0.1 \mu \mathrm{g} / \mathrm{L})$. Shakoaurian et al. [36] used the same approach to synthesise a TMU-6 based MFC to determine 3 organophosphorus pesticides in rice. In this case, $\mathrm{Fe}_{3} \mathrm{O}_{4}$ NPs functionalised with thioglycolic acid (ThGA) was mixed with zinc acetate, and the resulting product with the MOF principal ligand N,N-Bis[1-(pyridine-2-yl)ethylene]-benzene-1,4-diamine) (4-bpmb) and $\mathrm{H}_{2}$ oba gave $\mathrm{Fe}_{3} \mathrm{O}_{4} @$ ThGA@TMU-6 superparamagnetic NPs. Rice samples (2 g) were powdered, ultrasound extracted with $3 \mathrm{~mL}$ EtOH and centrifuged. Two $\mathrm{mL}$ of the supernatant was diluted in $23 \mathrm{~mL}$ water and submitted to the $\mathrm{m}$ - $\mu$-dSPE-HPLC-UV method using 1-butanol $(100 \mu \mathrm{L})$ 
as the elution solvent. The phenyl groups in the 4-bpmb ligand in $\mathrm{Fe}_{3} \mathrm{O}_{4} @$ ThGA@TMU-6 favour the adsorption of non-ionizable organophosphorus pesticides through $\pi-\pi$ stacking, hydrophobic and hydrogen bond formation, a fact that is demonstrated through the higher extraction efficiencies of the $\mathrm{Fe}_{3} \mathrm{O}_{4} @$ ThGA@TMU-6 composite with respect to that of $\mathrm{Fe}_{3} \mathrm{O}_{4} @$ ThGA. This nanomaterial could be used up to 20 times giving LODs between $0.5-1.0 \mu \mathrm{g} / \mathrm{L}$ and recovery values ranging from $88 \%$ to $107 \%$. In another work [37], $\mathrm{Fe}_{3} \mathrm{O}_{4} \mathrm{NPs}$ were functionalised with 1,3,5-triformylbenzene ( $\mathrm{Tb}$ ) and bencidine $(\mathrm{Bd})$ in dimethyl sulfoxide (DMSO) to give $\mathrm{Fe}_{3} \mathrm{O}_{4} @ \mathrm{TbBd}$ microspheres. They were then made to react with $\mathrm{HAuCl}_{4} \cdot \mathrm{H}_{2} \mathrm{O}$ in $\mathrm{MeOH}$ and the so-formed $\mathrm{Fe}_{3} \mathrm{O}_{4} @ \mathrm{TbBd}$-Au particles were finally dispersed in a mercaptoacetic acid EtOH solution to give rise to $\mathrm{Fe}_{3} \mathrm{O}_{4} @ \mathrm{TbBd}-\mathrm{Au}-\mathrm{COOH}$. These particles were added to a mixture of $\mathrm{Zn}\left(\mathrm{NO}_{3}\right)_{2} \cdot 6 \mathrm{H}_{2} \mathrm{O}$ and 2-methylimidazole to let $\mathrm{Fe}_{3} \mathrm{O}_{4} @ \mathrm{TbBd} @ \mathrm{ZIF}-8$ composite form. The adsorption capacity of this composite was compared with that of $\mathrm{Fe}_{3} \mathrm{O}_{4} @ \mathrm{TbBd}$, being higher due to the hydrophilic affinity and the $\pi-\pi$ stacking interactions of ZIF- 8 with the analytes, as well as to the pore filling effect which enhanced the van der Waals forces. Seven $\mathrm{mg}$ of it was dispersed in $10 \mathrm{~mL}$ of pork extract for the VA-m- $\mu$-dSPE of 8 sedative drugs after previous treatment of the samples with $\mathrm{ACN}, \mathrm{NaOH}$ and tert-butyl methyl ether. ACN was used as elution solvent $(1 \mathrm{~mL})$, obtaining good recovery values $(79-114 \%$ ) and LODs in the range $0.7-3.2 \mu \mathrm{g} / \mathrm{L}$. The material could be used up to 6 times after proper washing.

The last way to synthesise m-MOFs is the sealing technique, in which modified m-NPs are added to the MOFs precursor, giving rise to the coordination of organic ligands and metallic ions in the MOFs [38-40]. In general, MOFs suffer of low water stability, a fact that Niu et al. [38] tried to resolve by obtaining a ternary nanohybrid. Attapulgite (ATP) modified $\mathrm{F}_{3} \mathrm{O}_{4}\left(\mathrm{Fe}_{3} \mathrm{O}_{4} @ A T P\right)$ was mixed with $\mathrm{Zn}$ nitrate and then 2-methylimidazole was added to obtain $\mathrm{Fe}_{3} \mathrm{O}_{4} @ A T P @ Z I F-8$. The authors made a comparison of the extraction efficiency of 6 benzoylurea insecticides by $\mathrm{Fe}_{3} \mathrm{O}_{4} @ \mathrm{ATP}, \mathrm{Fe}_{3} \mathrm{O}_{4} @ \mathrm{ZIF}-8$ and $\mathrm{Fe}_{3} \mathrm{O}_{4} @$ ATP@ZIF-8, obtaining the better results for ATP@Fe $\mathrm{O}_{4} @ Z$ ZIF-8. This is probably due to the enhanced hydro-stability that ATP provides, increasing the number of adsorption sites. Thirty mg of the composite was used for the VA-m- $\mu$-dSPE of the selected pesticides in $8 \mathrm{~mL}$ of tea infusions using $2 \mathrm{~mL}$ ACN as the elution solvent. The phase could be used up to 5 times and provided good results in terms of recovery (79-114\%) and LODs in the range $0.7-3.2 \mu \mathrm{g} / \mathrm{L}$. Another work in which the m-MOF nanocomposite was obtained by the sealing method is that developed by Tadjarodi and Abbaszadeh [39], in which $\mathrm{Fe}_{3} \mathrm{O}_{4}$ particles were modified with 4-(5)-imidazoledithiocarboxylic acid (DTIM) and then made react with trimesic acid in $\mathrm{DMF} / \mathrm{EtOH}$. After the addition of a $\mathrm{Cu}$ (II) acetate solution, the $\mathrm{Fe}_{3} \mathrm{O}_{4} @$ DTIM@MOF-199 composite was obtained and used for $\mathrm{Hg}$ (II) extraction from fish and canned tuna $(0.5 \mathrm{~g})$ after acid digestion of the samples using $1.1 \mathrm{M}$ thiourea as the elution solvent $(3.5 \mathrm{~mL})$, obtaining a LOD of $10 \mathrm{ng} / \mathrm{L}$ and recovery values in the range $95-102 \%$. The sorbent could be reused up to 12 times and the effect of potentially interfering ions (K(I), $\mathrm{Na}(\mathrm{I}), \mathrm{Ca}(\mathrm{II}), \mathrm{Mg}(\mathrm{II})$, $\mathrm{Al}(\mathrm{III}), \mathrm{Fe}(\mathrm{III}), \mathrm{Cr}(\mathrm{III}), \mathrm{Mn}(\mathrm{II}), \mathrm{Pb}(\mathrm{II}), \mathrm{Zn}(\mathrm{II}), \mathrm{Ag}(\mathrm{I}), \mathrm{Ni}(\mathrm{II}), \mathrm{Co}(\mathrm{II}), \mathrm{Cd}(\mathrm{II}), \mathrm{CrO}_{4}{ }^{2-}$ and $\mathrm{AsO}_{4}{ }^{3-}$ ) was assayed and even at high concentrations, they did not affect the extraction of $\mathrm{Hg}$ (II) at $\mathrm{pH}=6.0$. Also in another occasion [40], magnetite NPs were mixed with tetraethyl orthosilicate (TEAS) in $\mathrm{NH}_{4} \mathrm{OH}$ solution to form $\mathrm{F}_{3} \mathrm{O}_{4} @ \mathrm{SiO}_{2}$ and then made react with 3-(chloropropyl)trimethoxysilane (3-CPTS) in toluene and later with 1-(2-pyridylazo)-2-naphthol (PAN) in MeOH:triethylamine (TEA) to form $\mathrm{Fe}_{3} \mathrm{O}_{4} @ \mathrm{SiO}_{2} @ P A N$. Then, they were mixed with benzene 1,4-dicarboxylic acid $\left(\mathrm{H}_{2} \mathrm{BDC}\right)$ and $\mathrm{Cr}\left(\mathrm{NO}_{3}\right)_{2}$ to give the nanocomposite $\mathrm{Fe}_{3} \mathrm{O}_{4} @ \mathrm{SiO}_{2} @ P A N @ M I L-101$. The extraction capabilities of raw MIL-101(Cr), $\mathrm{Fe}_{3} \mathrm{O}_{4} @ \mathrm{SiO}_{2} @ \mathrm{PAN}$ and $\mathrm{Fe}_{3} \mathrm{O}_{4} @ \mathrm{SiO}_{2} @ \mathrm{PAN} @ M I L-101$ were compared, providing the latter the best performance due to the combination of two facts: its higher surface area and the presence of PAN in the m-NPs as a proper chelator, which enhances the complex formation between nitrogen atoms and $\mathrm{Sn}(\mathrm{IV})$. Furthermore, the MIL-101(Cr) action as spacer was also noted, which prevents $\mathrm{Fe}_{3} \mathrm{O}_{4} @ \mathrm{SiO}_{2} @ \mathrm{PAN}$ aggregation, as well as the cation-exchange interactions between the negative sites of MIL-101(Cr) and hydrated Sn(IV) ions. The sorbent was used for the UA-m- $\mu$-dSPE of Sn(IV) from canned tuna fish, canned cherry and tomato paste (1 g sample) after acid digestion. Sn(II) could also 
be determined by oxidising it into $\mathrm{Sn}(\mathrm{IV})$. Only $0.75 \mathrm{~mL}$ of $1.25 \mathrm{M} \mathrm{HCl}$ was used as the elution solvent, obtaining. a LOD of $5.0 \mathrm{ng} / \mathrm{L}$ and recovery values between $87-96 \%$.

Apart from the aforementioned works, there are others in the literature which combine the use of $\mathrm{m}-\mathrm{MOF}$ with other systems to improve the extraction of the analytes [41,42]. This is the case of the work developed by Senosy et al. [41] in which ZIF-8 modified magnetic GO was employed to extract a group of triazole fungicides in honey and fruit juices. $\mathrm{Bare} \mathrm{Fe}_{3} \mathrm{O}_{4} \mathrm{~m}-\mathrm{NPs}$ were modified with (3-aminopropyl) triethoxysilane (APTES) in order to provide then with $-\mathrm{NH}_{2}$ groups. Then, $\mathrm{GO}$ powder was dispersed in DMF and n-hydroxyl succinimide (NHS) and (1-ethyl-3-(3-dimethylaminopropyl) carbodiimide (EDC) were added together with the $\mathrm{Fe}_{3} \mathrm{O}_{4} @$ APTES particles to finally form $\mathrm{Fe}_{3} \mathrm{O}_{4} @$ APTES-GO. Once dispersed in $\mathrm{MeOH}, \mathrm{Zn}\left(\mathrm{NO}_{3}\right)_{2} \cdot 6 \mathrm{H}_{2} \mathrm{O}$ was added to give rise to the $\mathrm{Fe}_{3} \mathrm{O}_{4} @$ APTES-GO@ZIF-8 nanocomposite. After dilution with water of the honey $(10 \mathrm{~g}$ in $100 \mathrm{~mL})$ and juice samples $(1: 2, v / v), 16 \mathrm{mg}$ of the phase were added to $30 \mathrm{~mL}$ of extract and submitted to $\mathrm{m}-\mu$-dSPE. MeOH was used as elution solvent $(0.5 \mathrm{~mL})$, obtaining a good recovery $(72-111 \%)$ and LODs in the range $0.014-0.109 \mu \mathrm{g} / \mathrm{L}$. The presence of GO sheets provided a better dispersion of the phase in aqueous solution. Another interesting work concerning m-MOFs combined with other phases is that developed by Du et al. [42], who described the synthesis of $\mathrm{F} \mathrm{Fe}_{3} \mathrm{O}_{4} @ \mathrm{MOF}-199-$-embebbed 2-ethylhexylacrylate (EHA)/divinylbenzene (DVB)/methyl methacrylate (MMA) polymerised high internal phase emulsion (polyHIPE) m-MOF composite by in situ polymerisation. PolyHIPEs have been employed in the last decade as sorbent materials due to their high specific surface area, high interconnected pore network and well-defined porosities; however, they showed low permeability and poor mechanical behavior if not combined with a more stable structure. The authors mixed the monomers MMA, DVB and EHA and the surfactant Span 80 with a $\mathrm{K}_{2} \mathrm{~S}_{2} \mathrm{O}_{8}$ solution which was dropwise added, followed by the addition of the previously synthesised $\mathrm{Fe}_{3} \mathrm{O}_{4} @ \mathrm{MOF}-199$. The prepared monolithic composites were cut into disks of $1.2 \mathrm{~cm}$ in diameter and $6.0 \mathrm{~mm}$ in thickness. The authors compared the surface area of the $\mathrm{Fe}_{3} \mathrm{O}_{4} @$ MOF-199/(EHA/DVB/MMA)polyHIPE with conventional (EHA/DVB/MMA)polyHIPEs, obtaining a lower value, but showing an obvious better mechanical strength. Magnetic-stir cake sorptive extraction (m-SCSE) was developed with the cut disks for the determination of 4 tetracycline antibiotics in $10 \mathrm{~mL}$ of milk, egg, chicken muscle and kidney extract after proper treatment of the samples. LODs were between 1.9 and $13.9 \mu \mathrm{g} / \mathrm{L}$ for milk and egg and between 1.8 and $13.0 \mu \mathrm{g} / \mathrm{kg}$ for chicken muscle and kidney. Recovery values were in all cases higher than $87 \%$.

\subsubsection{Combined with Polymeric Materials}

The presence of functional groups in polymers makes them ideal for their combination with $\mathrm{m}-\mathrm{NPs}$ [46]. This fact, together with the stability of polymers in a wide range of $\mathrm{pH}$, has become that combination very popular for the extraction of food samples [7]. It should be noted that, in contrast, the polymers are relatively unstable at high temperatures (a problem which is exacerbated by the possible catalytic behaviour of the metallic core) [47]. Some selected examples of the application of the mentioned combination are shown in Table 3 [48-57].

The interaction between polymers and m-NPs could occur through covalent or electrostatic (as a result of attractive magnetic force, steric hindrance and van der Waals interactions) mechanisms. The inclusion of polymers, as happens with other coatings, passivates the surface of m-NPs and avoids agglomeration [47]. If coating occurs simultaneously with the synthesis, particle growth is limited [47].

Both natural (agarose, chitosan, dextran, short-chain amylose) and synthetic polymers including non-imprinted polymer (NIP), such as polypyrrole, polydopamine (pDA), poly(diallyl dimethylammonium chloride), polystyrene, etc., MIPs and ion-imprinted polymers (IIPs) have been combined with m-NPs for food analysis. Normally, natural polymers are attached through electrostatic interaction whereas covalent bonding is involved for synthetic polymers [58]. A wide variety of analytes, including pesticides, dyes, antibiotics, vitamins, hormones, endocrine disruptors, antioxidants, mycotoxins, metals and other contaminants and natural organic compounds, have been extracted by m-polymeric NPs from different food matrices, comprising vegetables, fruits, beverages, cereals and derivatives, milk and dairy products, honey, meat and fish, among others. 
Table 3. Recent applications of magnetic polymeric nanomaterials as sorbents in food analysis.

\begin{tabular}{|c|c|c|c|c|c|c|c|}
\hline Analytes & Matrix & Nanomaterial & Extraction Technique & $\begin{array}{l}\text { Determination } \\
\text { Technique }\end{array}$ & $\begin{array}{c}\text { Recovery } \\
\%\end{array}$ & LOD & Reference \\
\hline Acrylamide & $\begin{array}{l}\text { Potato chips } \\
\quad(2 \mathrm{~g})\end{array}$ & $\begin{array}{c}\mathrm{Fe}_{3} \mathrm{O}_{4} @ \text { dextran@MIP } \\
(20 \mathrm{mg})\end{array}$ & $\mathrm{SLE}, \mathrm{m}-\mu-\mathrm{dSPE}$ & HPLC-UV & $84-97$ & $20 \mu \mathrm{g} / \mathrm{L}$ & [48] \\
\hline 6 Phenyl pesticides & $\begin{array}{l}\text { Apple, pear, cucumber, } \\
\text { lettuce and cherry } \\
\text { tomato }(50 \mathrm{~g})\end{array}$ & $\begin{array}{c}\mathrm{Fe}_{3} \mathrm{O}_{4} @ \mathrm{SiO}_{2} @ \text { poly (phenylene ethynylene) } \\
\text { framework } \\
(20 \mathrm{mg})\end{array}$ & UAE, m- $\mu$-dSPE & UHPLC-MS/MS & 80-119 & $0.27-3.1 \mathrm{ng} / \mathrm{L}$ & [49] \\
\hline Malachite green & $\begin{array}{l}\text { Fish } \\
(5 \mathrm{~g})\end{array}$ & $\mathrm{CdTe} \mathrm{QDs} / \mathrm{Fe}_{3} \mathrm{O}_{4} @ \mathrm{MIP}$ (0.8 mg) & $\mathrm{UAE}, \mathrm{m}-\mu-\mathrm{dSPE}$ & FD & 102-109 & $0.014 \mu \mathrm{mol} / \mathrm{L}$ & [50] \\
\hline $\begin{array}{l}22 \text { Oestrogenic } \\
\text { compounds }\end{array}$ & $\begin{array}{l}\text { Cow, goat, sheep and } \\
\text { human milk } \\
(1.5 \mathrm{~mL})\end{array}$ & $\begin{array}{l}\mathrm{Fe}_{3} \mathrm{O}_{4} @ \mathrm{pDA} \\
\quad(80 \mathrm{mg})\end{array}$ & $m-\mu-d S P E$ & UHPLC-MS/MS & $70-120$ & $0.55-11.8 \mu \mathrm{g} / \mathrm{L}^{\text {a) }}$ & [51] \\
\hline 3 Acaricides & $\begin{array}{l}\text { Grape, apple and peach } \\
\text { juice } \\
(8 \mathrm{~mL})\end{array}$ & $\begin{array}{c}\text { 1-hexadecyl-3- } \\
\text { methylimidazoliumbromide-coated } \\
\text { ATP@polyaniline-polypyrrole@ } \mathrm{Fe}_{3} \mathrm{O}_{4} \\
(1 \mathrm{mg})\end{array}$ & m-MHSPE & HPLC-DAD & $76-95$ & $0.16-0.57 \mu \mathrm{g} / \mathrm{L}$ & [52] \\
\hline $\begin{array}{c}\text { Clonazepam and } \\
\text { norazepam }\end{array}$ & $\begin{array}{l}\text { Herbal health food } \\
(0.5 \mathrm{~g})\end{array}$ & $\begin{array}{c}\mathrm{Fe}_{3} \mathrm{O}_{4} @ \mathrm{SiO}_{2} @ \mathrm{MIP} \\
(-)\end{array}$ & SBSE & HPLC-UV & $90-103$ & $0.01 \mu \mathrm{g} / \mathrm{mL}$ & [53] \\
\hline $\mathrm{Cd}(\mathrm{II})$ and $\mathrm{Pb}(\mathrm{II})$ & $\begin{array}{l}\text { Fish and shrimp }(0.5 \mathrm{~g}) \text {, } \\
\text { broccoli, apple, lettuce } \\
\text { andmushroom } \\
(1 \mathrm{~g})\end{array}$ & $\begin{array}{c}\mathrm{Fe}_{3} \mathrm{O}_{4} @ \mathrm{SiO}_{2} @ \text { polyaminoquinoline } \\
\text { (21 mg) }\end{array}$ & MAE, m- $\mu$-dSPE & FAAS & $86-102$ & $0.1-0.7 \mathrm{ng} / \mathrm{mL}$ & [54] \\
\hline $\begin{array}{l}5 \text { Polar acidic } \\
\text { herbicides }\end{array}$ & $\begin{array}{l}\text { Rice } \\
(5 \mathrm{~g})\end{array}$ & $\begin{array}{c}\mathrm{Fe}_{3} \mathrm{O}_{4} @ \text { polyethyleneimine@r-GO } \\
(5.4 \mathrm{mg})\end{array}$ & SLE, m-dSPE & HPLC-DAD & $87-103$ & $0.67-2.00 \mathrm{ng} / \mathrm{g}$ & [55] \\
\hline $\operatorname{Ag}(\mathrm{I})$ & $\begin{array}{l}\text { Rice, potato and tomato } \\
(1 \mathrm{~g})\end{array}$ & $\begin{array}{c}\mathrm{Fe}_{3} \mathrm{O}_{4} @ \mathrm{SiO}_{2} @ \mathrm{TiO}_{2} @ \mathrm{IIP} \\
(40 \mathrm{mg})\end{array}$ & m-dSPE & FAAS & 98-100 & $0.5 \mathrm{ng} / \mathrm{mL}$ & [56] \\
\hline $\begin{array}{l}\text { Bactrocera oleae } \\
\text { sexual pheromone }\end{array}$ & $\begin{array}{l}\text { Olive oil } \\
(10 \mathrm{~mL})\end{array}$ & $\begin{array}{l}\mathrm{Fe}_{3} \mathrm{O}_{4} @ \mathrm{SiO}_{2} @ \mathrm{MIP} \\
(50 \mathrm{mg})\end{array}$ & m-dSPE & GC-MS & $95-99$ & $3.2 \mu \mathrm{g} / \mathrm{L}$ & [57] \\
\hline
\end{tabular}

ATP: attapulgite; DAD: diode array detector; FAAS: flame atomic absorption spectrometry; FD: fluorescence detection; GC: gas chromatography; HPLC: high performance liquid chromatography; IIP: ion imprinted polymer; LOD: limit of detection; MAE: microwave assisted extraction; $\mathrm{m}$ - $\mu$-dSPE: magnetic-micro-dispersive solid-phase extraction; m-MHSPE: mixed hemimicelles solid-phase extraction; MIP: molecularly imprinted polymer; MS: mass spectrometry; MS/MS: tandem mass spectrometry; pDA: polydopamine; QD: quantum dot; r-GO: reduced-graphene oxide; SBSE: stir bar sorption extraction; SLE: solid-liquid extraction; UAE: ultrasound assisted extraction; UHPLC: ultra-high performance liquid chromatography; UV: ultraviolet. 
Polymers are frequently combined with other materials (in addition to m-NPs) to improve extraction capacity, physical properties or to facilitate interaction. Thus, examples can be found in the literature of the combination with $\mathrm{SiO}_{2}[49,53,54,56,57]$, carbonaceous materials [55,59], ionic liquids (ILs) [52] and quantum dots (QDs) [50]. It should be mentioned that, keeping in mind that the extraction mechanism involves different interactions when multi-material composites are used, some of the applications mentioned in this section could also be included in the preceding ones.

Silanisation is a typical method to modify m-NPs due to the low price, and chemical, mechanical and thermal inertness and stability $[46,58]$. Moreover, the chemistry of silica is well known and, thus, different arrangements are allowed (for example the combination of successive porous and non-porous layers). This total knowledge about silica facilitates an easier further modification, whereas the functionalisation of magnetite could sometimes be difficult. This is the reason why a high percentage of the applications that use polymers (and particularly MIPs) employed $\mathrm{Fe}_{3} \mathrm{O}_{4} @ \mathrm{SiO}_{2}$ as a substrate.

The combination with carbonaceous materials not only allows the possibility of including functional groups at the carbonaceous surface without disrupting the electronic network but also increases the adsorption sites of such material adding a further interaction mechanism, apart from the $\pi-\pi$ stacking offered by the carbon skeleton. Moreover, the dispersion in water of the carbonaceous m-NPs is enhanced. As an example, Li et al. [55] synthesised polyethyleneimine modified reduced graphene oxide m-NPs through self-assembling via electrostatic interaction of positive charged polyethyleneimine magnetite NPs and negative charged graphene oxide sheets. $\mathrm{Fe}_{3} \mathrm{O}_{4} \mathrm{NPs}$ were synthesised via a solvothermal method and polyethyleneimine composite was obtained via a crosslinking reaction. GO was exfoliated with deoxygenated water and ultrasounds and then mixed with magnetic polyethyleneimine NPs. Subsequently, $\mathrm{GO}$ was reduced with $\mathrm{NaBH}_{4}$. After being characterised by TEM, FT-IR, XRD, TGA, zeta potential analysis and VSM, the obtained material was employed for the extraction of polar acidic herbicides (dicamba, 2,4-dichlorophenoxy acetic acid, 4-chloro-methyl-phenoxy acetic acid, 2-(2,4-dichlorophenox) propionic acid, 2,4,5-trichlorophenoxy acetic acid) from rice by $\mathrm{m}$-dSPE with good results (recovery: $87.41-102.52 \%$, LODs: $0.67-2.00 \mathrm{ng} / \mathrm{g}$ ). The optimal conditions for parameters affecting extraction efficiency were obtained through a multivariate experimental design (i.e., response surface methodology) and the method proved to be comparable or even superior to other previous methods developed with the same aim.

Yang et al. [52] developed a magnetic mixed hemimicelles dSPE using an IL-coated ATP@polyaniline-polypyrrole@ $\mathrm{Fe}_{3} \mathrm{O}_{4}$ composite for the analysis of acaricides in fruit juice. The mechanism of the mixed hemimicelles dSPE involves the adsorption of ionic surfactants (ILs in this case) on metal oxides. At concentrations lower than the critical micelle, a single (hemimicelles) or double-layer (admicelles) is formed. The use of hemimicelles in SPE implicates high extraction efficiency, high breakthrough volumes and easy elution of the analytes. However, the protocol requires relatively high analysis times for the transference of the solvent to the column, due to the formation of these micellar structures. Thus, the use of dSPE procedures can overcome this disadvantage. In the mentioned application [52], the ATP@polyaniline-polypyrrole@ $\mathrm{Fe}_{3} \mathrm{O}_{4}$ was mixed with water and sonicated to form the magnetic fluid and added to the fruit juice. Then, $50 \mu \mathrm{L}$ of 1-hexadecyl-3-methylimidazolium bromide was added and sonicated for $2 \mathrm{~min}$ to trap the analytes in the hemimicelles. Factors affecting extraction efficiency (sorbent type, amount of composite, volume of $\mathrm{IL}$, sample $\mathrm{pH}$, extraction time and desorption conditions) were optimised and suitable recovery values (76-95\%), LODs $(0.16-0.57 \mu \mathrm{g} / \mathrm{L})$ and sorbent-to-sorbent repeatability (1.83-4.24\%) were obtained. Compared with other methods employed to extract acaricides, the developed protocol reduced the analysis time between 3 and 32 times.

The use of QDs is based on their noteworthy optical properties, including the broad absorption spectra, the size tenability, the narrow symmetric emission, and the photostability. The use of a co-nucleus of CdTe QDs and magnetite produced a fluorescent sorbent the combination of which with MIPs allowed the detection of malachite green (triphenylmethane dye) in fish [50]. The concentration of malachite green was determined through the ratio of fluorescence intensities of the m-NPs in the 
absence and presence of malachite green (quencher) using its quenching constant. This fluorescent material, synthesised by reverse microemulsion, provided a LOD of $0.014 \mu \mathrm{mol} / \mathrm{L}$ and recovery values in the range 103-109\%. Selectivity of the method was evaluated with leucomalachite green, crystal violet and brilliant green and NIP m-NPs.

Among the polymeric coating, microporous organic polymers can be an interesting alternative. Generally speaking, microporous organic polymers are composed of lightweight elements linked by covalent bonds that can be obtained from many different building blocks using different chemical reactions. Such polymers can be designed to obtain desirable properties and are characterised by the presence of pores smaller than $2 \mathrm{~nm}$ [60]. This kind of polymer can be classified on the following categories: Hyper-cross-linked-polymers, polymers of intrinsic microporosity, covalent organic frameworks, conjugated microporous polymers and porous aromatic frameworks. These kinds of materials have been used in many different research fields including sample preparation for food analysis. In this regard, their combination with m-NPs has provided good results [49,61]. For example, Lei et al. [49] synthesised magnetic poly(phenylene ethynylene)-conjugated microporous polymer microspheres for the extraction of 6 phenyl pesticides (meptyldinocap, picoxystrobin, mandipropamid, fenpropidine, ethoxyquin and pyraclostrobin) from fruits (apple and pear) and vegetables (cucumber, lettuce and cherry tomato). For this purpose, $\mathrm{Fe}_{3} \mathrm{O}_{4} \mathrm{NPs}$ were prepared by coprecipitation and treated with tetraorthosilicate to obtain $\mathrm{SiO}_{2}$ covered m-NPs. The conjugated three-dimensional network structure of poly (phenylene ethynylene) frameworks (Figure 3) was obtained by mixing $\mathrm{Fe}_{3} \mathrm{O}_{4} @ \mathrm{SiO}_{2}$-aminophenylacetylene particles with 1,3,5-tribromobenzene, 1,3,5-trialkynylbenzene in dimethyl formamide, bis(triphenylphosphine) palladium(II) chloride, CuI, triethylamine and toluene/water $(1: 1 \mathrm{v} / \mathrm{v})$. m-NPs, characterised by TEM, SEM, IR, magnetic analysis and $\mathrm{N}_{2}$ adsorption proved to have a size of $500 \mathrm{~nm}$. After validation of the method, the sorbent was applied in a dissipation study. After spraying lettuce and tomato, samples were collected and analysed between $2 \mathrm{~h}$ and 21 days. The half-life time for these compounds was in the range between 1.3-11.0 days. Finally, the method was applied to the analysis of apples and lettuces after sinking them in vinegar, $2 \%$ salt water, $2 \%$ soda water and water. Baking soda solution demonstrated to be the more efficient method to remove these harmful molecules.
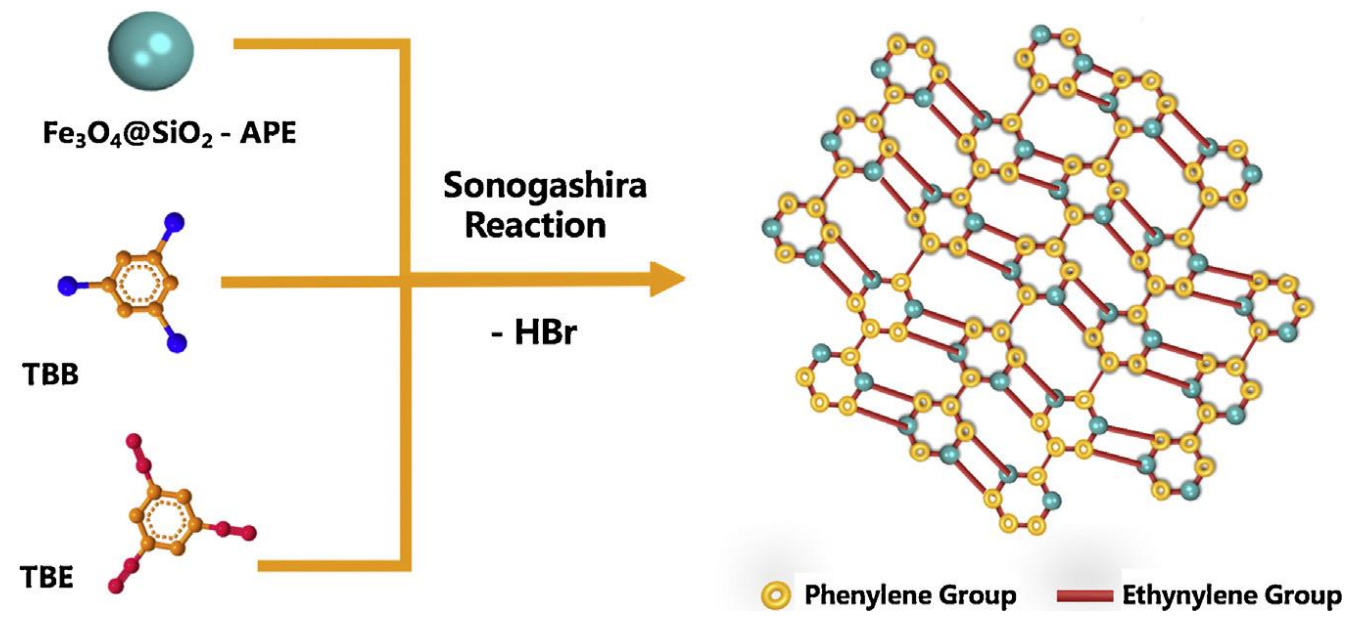

Figure 3. Synthesis of magnetic conjugated microporous polymer with conjugated three-dimensional network structure. Reprinted from [49] with permission from Elsevier, 2020.

The inclusion of MIPs is particularly interesting in sample preparation because of their inherent high selectivity. However, this selectivity can play a negative role if a multi-residue methodology is needed. Moreover, MIPs are frequently characterised by a heterogeneous distribution of the binding sites with poor site accessibility, low attaching capacity, incomplete template removal and slow binding kinetic. These drawbacks could be partially overcome by combining them with m-NPs, instead of 
using MIPs in the bulk state. Thus, it is not surprising that these kinds of mixture were used for food complex matrices. This way, a selective sorbent with superparamagnetism and good stability is obtained. Without any doubt, the great majority of applications of m-NPs combined with polymers for the analysis of foods have used a MIP $[48,50,53]$.

Another interesting alternative derived from the imprinted polymer technology is the use of IIPs. As happens with MIPs, IIPs offer mechanical and chemical stability, easy preparation, low cost and high affinity and selectivity for the separation, pre-concentration or removal of target ions. Analogously to MIPs, the main drawback is the limited active surface, so the inclusion of m-NPs helps to overcome this problem. The base molecules to construct the IIPs are ligands. For instance, Jalilian and Taheri [56] obtained $\mathrm{Fe}_{3} \mathrm{O}_{4} @ \mathrm{SiO}_{2} @ \mathrm{TiO}_{2}$ as magnetic support and synthesised the IIP using Ag(I)-2,4-diamino-6-phenyl-1,3,5-triazine complex as the template molecule, methacrylic acid as the functional monomer, 2,2'-azobisisobutyronitrile as the radical initiator and ethylene glycol dimethacrylate as crosslinker. The composite was employed for the extraction of silver from $1 \mathrm{~g}$ of rice, potato and tomato after acidic digestion with $10 \mathrm{~mL}$ concentrated $\mathrm{HNO}_{3}$ followed by the addition of $2 \mathrm{~mL}$ of $30 \% \mathrm{H}_{2} \mathrm{O}_{2}$. The extraction, performed with $40 \mathrm{mg}$ of the magnetic material, provided recovery values in the range of $97.5-100.5 \%$ and ideal selectivity in presence of coexisting ions ( $\mathrm{Na}(\mathrm{I}), \mathrm{K}(\mathrm{I}), \mathrm{Pb}(\mathrm{II})$, $\mathrm{Cd}(\mathrm{II})$ and $\mathrm{Ni}(\mathrm{II})$ ). The composite was also employed for the analysis of radiology film, tap, well and waste water and could be re-used 8 times.

Finally, it should be mentioned that although m-dSPE was the most common extraction technique, this kind of particle was also adequate for other methodologies [52,53]. In this regard, Li et al. [53] developed a stir bar coated with $\mathrm{Fe}_{3} \mathrm{O}_{4} @ \mathrm{SiO}_{2} @ \mathrm{MIP}$ NPs for the extraction of clonazepam and norazepan from herbal health food matrices (recovery values: 89.8-103.3\%, LOD: $0.01 \mu \mathrm{g} / \mathrm{mL}$ ) and Yang et al. [52], as it was previously mentioned, employed a 1-hexadecyl-3- methylimidazolium bromide -coated ATP@polyaniline-polypyrrole@ $\mathrm{Fe}_{3} \mathrm{O}_{4}$ composite in m-mixed hemimicelles SPE.

\subsection{Recent Applications in Sensors}

\subsubsection{Optical Sensors}

The operating principle of optical sensors is the existence of transducers that transform optical signals (ultraviolet, visible, infrared radiation, etc.) emitted by a chemical/biological/physical reaction into data [1,62]. Table 4 shows a selection of recent applications of optical sensors to the food analysis field [63-72], including sensors using colorimetry [63,64], fluorescence [65,66], chemiluminescence $[67,68]$, surface plasmon resonance (SPR) [69,70] and surface-enhanced Raman spectroscopy (SERS) [71,72].

Colorimetric sensors are based on the change of colour that can be detected by the naked eye and they have attracted interest because they are simple and fast and provide real-time detection $[1,62]$. This is the case of the work that Seddaoui and Amine developed for the detection of immunoglobulin $\mathrm{G}$ (IgG) for identifying meat adulteration [63]. Authors coated $\mathrm{Fe}_{3} \mathrm{O}_{4} \mathrm{~m}-\mathrm{NPs}$ with pDA and then covalently immobilised standard pig IgG onto the pDa@ $\mathrm{Fe}_{3} \mathrm{O}_{4}$ particles (pDa@Fe $\mathrm{O}_{4} @$ standard pig-IgG). The non-reacted groups were blocked with bovine serum albumin (BSA) and then the pig meat-extracted proteins were added together with anti-pig IgG polyclonal antibody (pAb) conjugated with horseradish peroxidase (HRP). In this way, a competitive assay took place between purified IgGs and porcine IgGs for the binding sites of peroxidase-labelled Ab. Porcine IgG was monitored by optical density of the reaction product at $450 \mathrm{~nm}$ in the presence of peroxidase substrate. This magneto-immunoassay allowed the detection of $0.01 \%$ pork in meat mixtures in a simple, sensitive and selective way. Another interesting work based on colorimetric sensing was that developed by Guan et al. [64], in which a sensor based on gold and m-NPs, as an enzyme mimetic of HRP, was constructed for the detection of cholesterol in egg yolk. Gold NPs were synthesised by an eco-friendly method based on the reduction with orange peel aqueous extract of chloroauric acid $\left(\mathrm{HAuCl}_{4}\right)$, and then made to react with amino-modified $\mathrm{Fe}_{3} \mathrm{O}_{4}$ m-NPs to obtain an $\mathrm{Au} @ \mathrm{Fe}_{3} \mathrm{O}_{4}$ m-NPs solution. Saponification of egg yolk was accomplished by addition of $2 \mathrm{M} \mathrm{KOH}$ and $10 \mathrm{~mL} \mathrm{EtOH}$ and after dilution with 
water, liquid-liquid extraction (LLE) with ether was carried out and finally, the extract evaporated and reconstituted with $\mathrm{EtOH}$. One hundred $\mu \mathrm{L}$ of cholesterol oxidase $(1 \mathrm{~g} / \mathrm{L})$ and $300 \mu \mathrm{L}$ of the sample extract in $500 \mu \mathrm{L}$ of $10 \mathrm{mM}$ phosphate buffered saline (PBS) were incubated at $37^{\circ} \mathrm{C}$ and after $30 \mathrm{~min}$, $100 \mu \mathrm{L}$ of $0.1 \mathrm{~g} / \mathrm{mL} \mathrm{Au@Fe} \mathrm{O}_{4}$ solution and $3 \mathrm{~mL}$ of $0.1 \mathrm{M} \mathrm{HAc}-\mathrm{NaAc}$ buffer solution were added. The reaction was inhibited with 2 '-azino-bis(3-ethylbenzothiazoline-6-sulfonic acid) (ABTS) and absorbance of the supernatant was measured at $420 \mathrm{~nm}$. Au@ $\mathrm{Fe}_{3} \mathrm{O}_{4}$ can catalytically oxidise ABTS in the presence of $\mathrm{H}_{2} \mathrm{O}_{2}$ to produce a typical green colour, with $\mathrm{H}_{2} \mathrm{O}_{2}$ coming from the reaction of cholesterol oxidase with cholesterol. The LOD was determined in $7.9 \mu \mathrm{M}$ and recovery values ranged from $99 \%$ to $107 \%$.

Fluorescence sensors are normally highly sensitive and selective [1,62]. Li et al. [65] used a lanthanide-doped upconversion NPs (UCNPs)-based sensor to analyse E. coli in pork meat after akaline peptone treatment to precipitate macroaggregates and seston. An E. coli Apt was linked to m-NPs and acted as a capture probe, while conjugated DNA (cDNA) linked to UCNPs worked as a signal probe. The whole m-NPs@Apt@cDNA@UCNPs platform, in the presence of E. coli, showed a decrease in the fluorescence emission at $662 \mathrm{~nm}$. The method was demonstrated to be specific in the presence of other bacteria (S. aureus and S. typhimurium), showed good recovery values (97-107\%) and had a LOD of 10 colony forming units (CFU)/mL. Wang and co-workers [66] described a lateral flow assay (LFA) strip using dense carboxylated QDs on the surface of polyethyleneimine (PEI) modified $\mathrm{Fe}_{3} \mathrm{O}_{4}$ m-NPs to capture and enrich two toxins, botulinum neurotoxin type A(BoNT/A) and staphylococcal enterotoxin (SEB), and serve as fluorescent labels. Figure 4 shows a scheme of the magnetic-quantum dots (m-QDs) preparation. Briefly, $\mathrm{Fe}_{3} \mathrm{O}_{4}$ were prepared from $\mathrm{FeCl}_{3}$ with $\mathrm{EG}$ and diethylene glycol (DEG) using sodium acetate as alkali source and polyvinylpyrrolidone (PVP) as stabiliser. Then, the m-NPs were coated with PEI and afterwards, carboxyl-functionalised CdSe/ZnS QDs were absorbed on the $\mathrm{Fe}_{3} \mathrm{O}_{4} @ P E I$ surface. Immuno-Fe $\mathrm{O}_{4} @ P E I @ Q D s$ were prepared conjugating BoNT/A or SEB Ab onto the $\mathrm{Fe}_{3} \mathrm{O}_{4} @ P E I @ Q D s$ surface by carbodiimide reaction. The figure also shows the mechanism of the method using two test lines, BoNT/A and SEB mAb and one control line (polyclonal goat anti-mouse IgG), which was applied to milk and grape juice without sample treatment, obtaining good recovery values (82-95\%) and a LOD of $2.52 \mathrm{ng} / \mathrm{L}$ for BoNT/A and $2.86 \mathrm{ng} / \mathrm{L}$ for SEB.

Chemiluminescence-based sensors have attracted interest due to their advantages, such as simplicity, low cost, wide linear range and good sensitivity $[1,62]$. Regarding its coupling with m-NPs for their use in food analysis, two recent papers are highlighted in this review. Jie et al. [67] developed a magnetic enzyme chemiluminescence immunoassay (MECLIA) using $\mathrm{Fe}_{3} \mathrm{O}_{4} @ \mathrm{Au}$ particles to detect fumonisin $\mathrm{B}_{1}$ in corn and wheat. Sample extraction was accomplished with $\mathrm{MeOH} /$ water (75:25 v/v) and the PBS diluted extract was submitted to the MECLIA. $\mathrm{Fe}_{3} \mathrm{O}_{4} @ \mathrm{Au}$ particles were synthesised by reduction of $\mathrm{Au}$ (III) onto $\mathrm{Fe}_{3} \mathrm{O}_{4}$ NPs previously generated by coprecipitation. Then, they were coated with fumonisin $B_{1}$-ovalbumin for binding with fumonisin $B_{1}$ Abs and put on a microplate of a 96 microplate reactor. HRP-IgG was conjugated with fumonisin $\mathrm{B}_{1} \mathrm{Abs}$ and in luminol- $\mathrm{H}_{2} \mathrm{O}_{2}$ medium, HRP-IgG catalysed luminol oxidation by $\mathrm{H}_{2} \mathrm{O}_{2}$, giving a high chemiluminescence signal. Recovery values in the range $98-110 \%$ and a LOD of $0.027 \mu \mathrm{g} / \mathrm{L}$ were obtained. Cross-reactivity was assayed with other toxins, showing a very good specificity. On the other hand, Hao and co-workers [68] detected Salmonella typhimurium in pork through a quite complex sensitive steady-state chemiluminescence aptasensor based on rolling circle amplification. Avidin, as S. typhimurium Apt, was immobilised in $\mathrm{Fe}_{3} \mathrm{O}_{4}$ m-NPs, so the target molecule could be trapped by them (recognition molecules and capture probes). Then, $\mathrm{Co}(\mathrm{II})$ enhanced $\mathrm{N}$-(aminobutyl)-N-(ethylisoluminol) (ABEI) functionalised flowerlike gold NPs (AuNFs) and cDNA complex (Co(II)/ABEI-AuNFs-cDNA) were used as signal probes to produce and enhance chemiluminescence signal. $p$-iodophenol (PIP) was added to form an ABEI-AuNFs-PIP- $\mathrm{H}_{2} \mathrm{O}_{2}$ steady-state chemiluminescence system. Pork samples were treated with $0.01 \mathrm{M}$ phosphate buffer solution $(5 \mathrm{~g}, 10 \mathrm{~mL})$ and after centrifugation, the supernatant was submitted to the chemiluminescence assay. The LOD was estimated in $10 \mathrm{CFU} / \mathrm{mL}$ and recovery values ranged between $87 \%$ and $101 \%$. The use of m-NPs in this work helped to produce a rapid separation and purification, reducing the assay time. 
Table 4. Novel applications of magnetic nanoparticles based on optical sensors in food analysis.

\begin{tabular}{|c|c|c|c|c|c|c|}
\hline Analytes & Matrix & Nanomaterial & $\begin{array}{l}\text { Determination } \\
\text { Technique }\end{array}$ & Recovery \% & LOD & Reference \\
\hline $\operatorname{IgG}$ & $\begin{array}{l}\text { Pork meat } \\
\quad(2 \mathrm{~g})\end{array}$ & $\mathrm{Fe}_{3} \mathrm{O}_{4} @ \mathrm{pDA}$ & Colorimetry & - & $0.01 \%$ & {$[63]$} \\
\hline Cholesterol & $\begin{array}{l}\text { Egg yolk } \\
(1 \mathrm{~g})\end{array}$ & $\mathrm{Fe}_{3} \mathrm{O}_{4} @ \mathrm{Au}$ & Colorimetry & 99-107 & $7.9 \mu \mathrm{M}$ & {$[64]$} \\
\hline Escherichia coli & $\begin{array}{l}\text { Pork meat } \\
\quad(25 \mathrm{~g})\end{array}$ & $\mathrm{Fe}_{3} \mathrm{O}_{4} @ \mathrm{Apt} @ \mathrm{cDNA} @ \mathrm{UCNPs}$ & Fluorescence & $97-107$ & $10 \mathrm{CFU} / \mathrm{mL}$ & [65] \\
\hline BoNT/A, SEB & $\begin{array}{l}\text { Milk, grape juice } \\
\text { (1 } \mathrm{mL})\end{array}$ & $\mathrm{Fe}_{3} \mathrm{O}_{4} @ \mathrm{PEI} @ \mathrm{CdSe} / \mathrm{ZnSQDs}$ & Fluorescence & $82-95$ & $2.52-2.86 \mathrm{ng} / \mathrm{L}$ & {$[66]$} \\
\hline Fumonisin $B_{1}$ & $\begin{array}{c}\text { Corn, wheat } \\
\text { (5 g) }\end{array}$ & $\mathrm{Fe}_{3} \mathrm{O}_{4} @ \mathrm{Au}$ & Chemiluminiscence & $98-110$ & $0.027 \mu \mathrm{g} / \mathrm{L}$ & [67] \\
\hline $\begin{array}{c}\text { Salmonella } \\
\text { typhimurium }\end{array}$ & $\begin{array}{l}\text { Pork meat } \\
\quad(5 \mathrm{~g})\end{array}$ & $\mathrm{Fe}_{3} \mathrm{O}_{4} @ \mathrm{Apt}$ & Chemiluminiscence & $87-104$ & $10 \mathrm{CFU} / \mathrm{mL}$ & {$[68]$} \\
\hline Estradiol & $\begin{array}{c}\text { Milk } \\
(1 \mathrm{~mL})\end{array}$ & estradiol-mAb-m-NPs & SPR & $88-114$ & $0.814 \mu \mathrm{g} / \mathrm{L}$ & [69] \\
\hline Salmonella enteritidis & $\begin{array}{l}\text { Egg shell } \\
(5 \mathrm{~g})\end{array}$ & $\mathrm{Ab} @ \mathrm{Fe}_{3} \mathrm{O}_{4}$ & SPR & $93-113$ & $<14 \mathrm{CFU} / \mathrm{mL}$ & {$[70]$} \\
\hline $\begin{array}{l}\text { Salmonella } \\
\text { typhimurium }\end{array}$ & $\begin{array}{c}\text { Egg white, cheese, } \\
\text { packaged juice } \\
(-)\end{array}$ & FP-m-NPs & SERS & $86-115$ & 10 cells/mL & {$[71]$} \\
\hline Aflatoxin $\mathrm{B}_{1}$ & $\begin{array}{l}\text { Peanut oil } \\
\quad(5 \mathrm{~g})\end{array}$ & $\mathrm{Fe}_{3} \mathrm{O}_{4}$-chitosan-Apt & SERS & 95-109 & $0.54 \mathrm{ng} / \mathrm{L}$ & {$[72]$} \\
\hline
\end{tabular}

Ab: antibody; Apt: aptamer; BoNT/A: botulinum neurotoxin type A; cDNA: complementary DNA; CFU: colony forming unit; FP-m-NPs: functionalised polymeric magnetic nanoparticles; IgG: immunoglobulin G; LFIA: lateral flow immunoassay; mAb: monoclonal antibody; m-NP: magnetic nanoparticle; NP: nanoparticle; pDA: polydopamine PEI: polyethylenimine; QD: quantum dot; SEB: staphylococcal enterotoxin B; SERS: surface-enhanced Raman spectroscopy; SPR: surface plasmon resonance; UCNP: lanthanide -upconversion nanoparticle. 


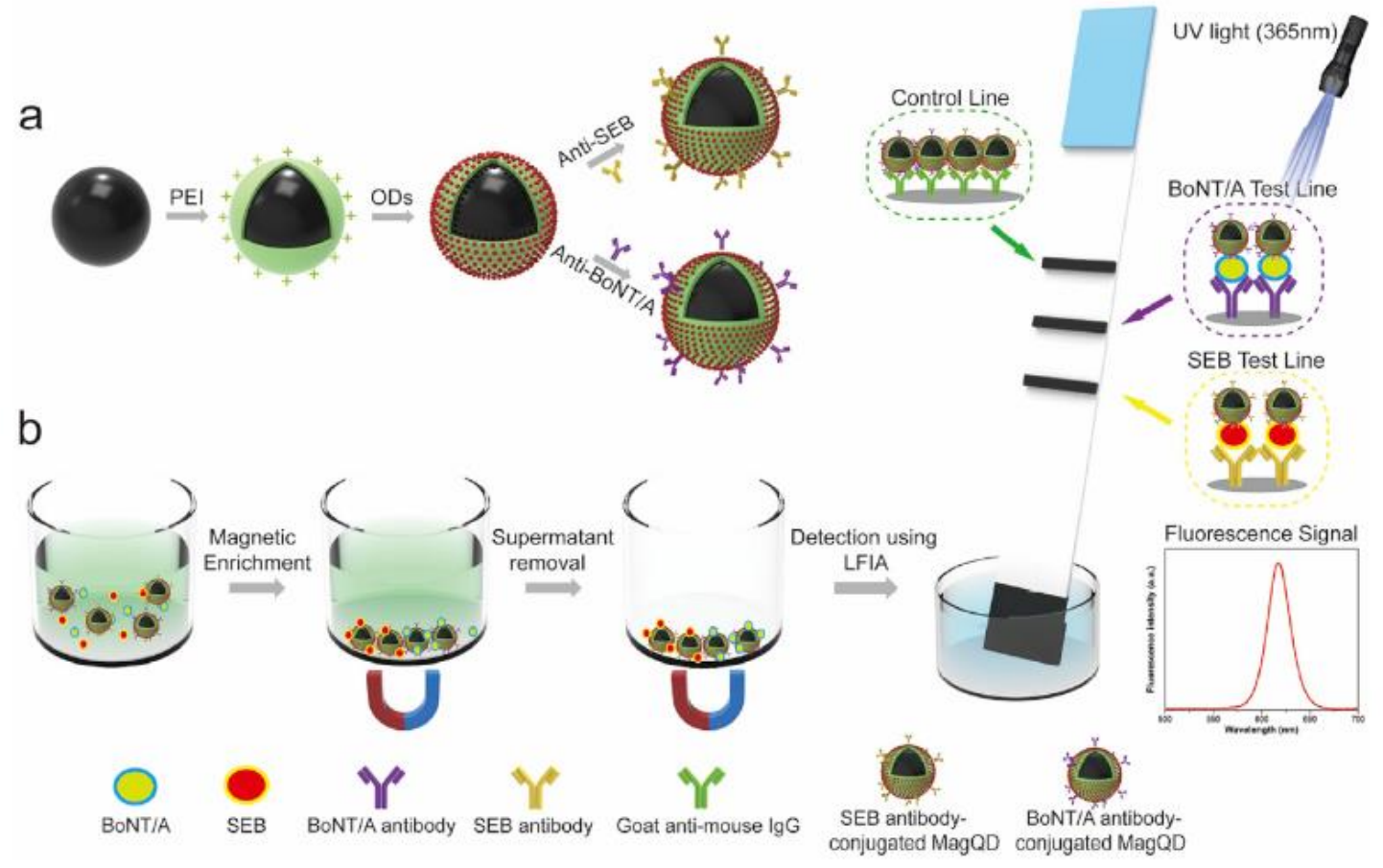

Figure 4. (a) Scheme of antibody (Ab)-modified magnetic-quantum dots (m-QDs) preparation and (b) mechanism of m-QDs-based lateral flow immunoassay (LFIA) strip for simultaneous and sensitive detection of two protein toxins. Reprinted from [66] with permission from Elsevier, 2020.

SPR sensors are refractometric sensors based on the changes in the refractive index on the sensor surface because of chemical, biological or physical events [1,62]. Jiu et al. [69] analysed estradiol in milk using a SPR biosensor system using m-NPs as amplifying elements. Anti-estradiol mAb was conjugated with m-NPs (Nanomag-D spio $20 \mathrm{~nm}$ NPs coated by dextran matrix and protein A) via protein A. Chitosan was coated on the sensor surface to immobilise the antigen estradiol-BSA using glutaraldehyde. Estradiol present in the sample could competitively bind estradiol-BSA and anti-estradiol-mAb and, therefore, cause a decrease of the SPR signal due to the diminution of estradiol-BSA and anti-estradiol-mAb concentration. m-NPs showed good capability of amplifying SPR signal, which resulted in a high sensitivity for estradiol detection. The method could be applied to milk samples after extraction of estradiol with ethyl acetate and the authors demonstrated its selectivity against other analogue molecules (diethylestilbestrol, dienestrol, hexestrol or estrone). They also compared the results obtained with this enhanced sensor with a traditional SPR sensor based on CS modified chip and an enzyme-linked immunosorbent assay (ELISA), showing in general better results. The LOD was $0.814 \mu \mathrm{g} / \mathrm{L}$ and the recovery values were in the range $88-114 \%$. Another interesting work dealing with SPR sensors was that developed by Liu et al. [70], who worked on a SPR immunosensor to analyse Salmonella enteritidis in eggshell after simple buffer extraction. First, $\mathrm{Ab}-\mathrm{Fe}_{3} \mathrm{O}_{4} \mathrm{~m}-\mathrm{NPs}$ were used to recognise and isolate, by an external magnetic field, the bacteria from the sample matrix. Afterwards, $\mathrm{S}$. enteritidis-Ab- $\mathrm{Fe}_{3} \mathrm{O}_{4}$ conjugates were put on the sensor surface modified with anti-S. enteritidis $\mathrm{pAb}$. S. enteritidis- $\mathrm{Ab}-\mathrm{Fe}_{3} \mathrm{O}_{4} \mathrm{~m}-\mathrm{NPs}$ worked both as carriers of the target analyte from the sample to the sensor surface, and also to increase the refractive index changes. Selectivity studies were carried out in the presence of Escherichia coli K12 ER2738 and Lactobacilus LK-3, obtaining an SPR signal more than 5500 times higher than for the other bacteria. A LOD lower than $14 \mathrm{CFU} / \mathrm{mL}$ was obtained with recovery values between $93 \%$ and $113 \%$. The method was compared with SPR immunosensor based on direct detection (without m-NPs), clearly obtaining a higher concentration range and a 1000-times better LOD.

SERS sensors have become interesting due to their high sensitivity and specificity $[1,62]$. Chattopadhyay and co-workers [71] described a SERS immunosensor for detecting Salmonella 
typhimurium in egg white, cheese and packaged juice (after proper PBS buffer extraction, except for juice) using functionalised polymeric m-NPs (FP-m-NPs), synthesised by in situ emulsion polymerisation of 3 monomers (styrene, MMA and 2-(methacryloyloxy)ethyl acetoacetate) along with stabilised $\mathrm{Fe}_{3} \mathrm{O}_{4} \mathrm{NPs}$, as capture probe. This probe contained diketonic functionalities in its surface that covalently linked with amino groups in Ab against Salmonella structural antigen (CSA-1-Ab). Au-NPs@CSA-1-Ab and 4-mercapto benzoic acid and 5,5'-dithiobis(succinimidyl-2-nitrobenzoate) (DSNB) as external Raman reporter molecules (RRM), were used as signal probes. Capture and signal probes linked the target bacteria generating Raman signal. The LOD was calculated in 10 cells/mL and recovery values ranged 86-115\%. Yang et al. [72] developed a quite complex SERS aptasensor based on the use of Apt modified $\mathrm{CS}$ modified $\mathrm{Fe}_{3} \mathrm{O}_{4}$ superparamagnetic particles $\left(\mathrm{Fe}_{3} \mathrm{O}_{4}\right.$-CS-Apt) as capture probes for aflatoxin $\mathrm{B}_{1}$; while gold nanotriangles (GNT)-5,5'-dithiobis (2-nitrobenzoic acid) (DTNB)@Ag-DTNB-Apt were used as the Raman reporter probes. This gave rise to the detection platform GNT-DTNB@Ag-DTNB-Apt-aflatoxin $\mathrm{B}_{1}$-Apt-CS- $\mathrm{Fe}_{3} \mathrm{O}_{4}$, which was applied to real peanut oil samples, obtaining recovery values between $95 \%$ and $109 \%$ and a very low LOD of $0.54 \mathrm{ng} / \mathrm{L}$. Authors also demonstrated the selectivity of the method against aflatoxin $B_{1}$ in the presence of other toxins such as ochratoxin $A$ and aflatoxin $G_{1}$.

\subsubsection{Electrochemical Sensors}

The particular characteristics of m-NPs in terms of large surface area, physicochemical nature, electrochemical and magnetic properties, as well as their easy modification make them adequate candidates as transducers in electrochemical sensors. Indeed, they have been used in different applications in the field of food analysis as can be observed in Table 5, in which some of the most relevant applications have been compiled [16,73-78]. These kinds of systems involve the use of reference, work and counter electrodes. It is in the latter in which the use of nanostructures and, particularly, m-NPs plays an important role to increase the sensitivity and selectivity of the detection system. This fact is related to their capability to enhance the signal as result of their good conductivity and the establishment of specific interactions with target analytes, including biomolecules $[1,62]$. In the field of food analysis the application of electrochemical sensors has been performed for the evaluation of both inorganic species $[16,75,76]$ and organic compounds, including proteins, hormones, contaminants, etc. $[73,74,77,78]$ in matrices of different nature such as seafood, fish and meat $[73,79]$, milk [76-78], vegetables [74], oil, tea and sugar [16] or fruit juice [75].

Electrochemical sensors are based on the electrochemical signal changes associated with the result of a chemical reaction between the target analytes and a recognition element located at the electrode. Among the elements used in the last few years in the area of food analysis there is a great variety including Abs [73,76], peptides combined with specific recognition structures, based on MIPs [77], polymers [78], DNA based Apts [74,79] or enzymes [75]. However, the evaluation of metallic species was carried out using a nanostructure-modified carbon paste electrode (CPE) without additional elements. In this case, Mohamed et al. [16] developed a simple procedure to carry out the evaluation of $\mathrm{Cu}(\mathrm{II})$ in oil, sugar and tea samples using differential pulse anodic stripping voltammetry (DP-ASV), after sample pre-treatment using an acidic extraction for oil samples and a combination of heating at $525^{\circ} \mathrm{C}$ followed by acidic extraction for sugar and tea samples. The nanostructure was constituted by $\mathrm{CoFe}_{2} \mathrm{O}_{4}$ NPs since this metal oxide has a high surface area, as well as a porous spinel structure with adequate characteristics for the determination of heavy metals. Results showed very good performance of the prepared electrode, obtaining a high recovery $(99 \%)$ and a low LOD $(0.085 \mu \mathrm{g} / \mathrm{L})$, as well as great stability, acceptable selectivity, excellent repeatability and reproducibility.

Despite the fact that Apts and Abs provide very specific interactions with the target analytes and lead to high selectivity, their combination with additional specific elements has also been developed in this field. An interesting example that illustrates such an approach is the work carried out by Han et al. [77], in which the combination of a peptide, glutathione (GSH) and a MIP was applied for the recognition of estradiol in milk powder samples using a glassy carbon electrode (GCE) modified by $\mathrm{Au}$ and $\mathrm{Fe}_{3} \mathrm{O}_{4}$ NPs. In this case, the authors combined the advantages of the great specificity given by 
the linker elements with the benefits of using a magnetic system to simplify the procedure reaching also high selectivity. As can be seen in Figure 5, GSH was bound to the $\mathrm{Au} @ \mathrm{Fe}_{3} \mathrm{O}_{4} \mathrm{NPs}$ for electrode preparation. Then, estradiol, used as template, was linked to this one by specific interactions prior to polymerisation to create the MIPs. For analysis performance, the electrode set up was assembled by the location of an external magnet on the GCE and introduced in the sample solution containing the MIP. After differential pulse voltammetry (DPV) measurements the magnet was removed and the estradiol@MIP was again released to the initial solution. Authors demonstrated that the incorporation of the MIP element increased the selectivity of the sensor even when similar chemical structures such as estriol or estrone were present. In addition, the use of $\mathrm{Au}$ NPs avoids $\mathrm{Fe}_{3} \mathrm{O}_{4} \mathrm{NPs}$ oxidation and aggregation, increasing device stability, and also enhances the conductivity of the material.

Depending on the electrochemical signal measurement mode, different kinds of sensors can be selected. In general terms, different modalities of amperometric [73,74] and voltammetric [75-78] sensors have been applied recently in this area based on the evaluation of the variation of the current potential in the work electrode, as a result of a redox transformation that involves the target analyte and the recognition element [1]. In this sense, differential pulse voltammetry has been the most used [76-78], although cyclic voltammetry (CV) [75], DP-ASV [16], and square wave stripping voltammetry (SWSV) [79] have also been tested, providing good sensitivity.

Regarding the type of transducer, $\mathrm{Fe}_{3} \mathrm{O}_{4}$ NPs have been the m-NPs mostly used [73-78], however, $\mathrm{CoFe}_{2} \mathrm{O}_{4}$ was also tested [16] as a modifier of sensor platforms in combination with recognition elements. In some cases, the combination with other nanomaterials has also shown very good results, including graphene [78] and GO [75], metal NPs [74,77,79] or QDs [79]. This strategy allows increasing the specificity of the interaction with the target analytes and improving the electrochemical features of the modified sensors as it was pointed out by Chen et al. [79]. In this work, authors developed a sensor based on $\mathrm{Au} @ \mathrm{Fe}_{3} \mathrm{O}_{4}$ NPs using a strand DNA Apt modified with PbS and CuS QDs for the analysis of chloramphenicol and polychlorinated biphenyl-72 (PCB72) in fish, using SWSV. The determination was based on one-step substitution reaction between the Apt(DNA)@QDs nanotracers and the target analytes on the sensor system. When such a replacement took place, Apt(DNA)@QDs were released into the solution and they could be simultaneously detected by SWSV of $\mathrm{Cu}$ (II) and $\mathrm{Pb}$ (II). The QDs acted as electrochemical tracers thanks to their well-defined oxidation potential which allowed enhancing the electrochemical signal. This fact, together with the advantages already mentioned about the combination of $\mathrm{Au}$ and $\mathrm{Fe}_{3} \mathrm{O}_{4} \mathrm{NPs}$, led to a very sensitive method with an LOD of $0.057 \mu \mathrm{g} / \mathrm{L}$. Apart from that, Apt(DNA)@QDs were linked to the magnetic composite by a dendric complex constituted by a large number of HRP and secondary Abs that provided a great number of enzyme sites where the nanotracer can be bound, increasing the number of active points and, consequently, the effectiveness of the sensor which provided recovery values in the range 96-105\%, even with such a complex samples like fish matrices.

As can be seen in this section, electrochemical sensors based on m-NPs allow the preparation of very simple and easily handled procedures as a result of the magnetic properties of this nanomaterial. These characteristics, in combination with the great surface area of NPs, as well as the great conductivity of these materials, the specificity given by the use of selective recognition elements and the benefits of including some other nanomaterials in the same applications, make the use of this kind of approaches an excellent alternative for the development of sensitive and selective strategies for the evaluation of a huge number of organic and inorganic compounds, even in very complex matrices as occurs with food samples. 
Table 5. Novel applications of magnetic nanoparticles based on electrochemical sensors in food analysis.

\begin{tabular}{|c|c|c|c|c|c|c|}
\hline Analytes & Matrix & Nanomaterial & $\begin{array}{l}\text { Determination } \\
\text { Technique }\end{array}$ & Recovery \% & LOD & Reference \\
\hline Tropomyosin & $\begin{array}{l}\text { Pork, beef, chicken, } \\
\text { shrimp and squid } \\
(1 \mathrm{~g})\end{array}$ & $\mathrm{Ab} @ \mathrm{Fe}_{3} \mathrm{O}_{4}$ & Amperometry & - & $47 \mathrm{ng} / \mathrm{L}$ & [73] \\
\hline $\begin{array}{l}\text { Genetically modified } \\
\text { organisms (RR } \\
\text { soybean and lectin } \\
\text { gene target) }\end{array}$ & $\begin{array}{c}\text { Soybean } \\
(-)\end{array}$ & $\begin{array}{l}\text { Apts(DNA)@Amercaptohexanoic } \\
\text { acid@Au@ } @ \mathrm{Fe}_{3} \mathrm{O}_{4} @ \text { GCE }\end{array}$ & aronoamperometry & - & $0.02-0.05 \mathrm{nM}$ & {$[74]$} \\
\hline $\mathrm{H}_{2} \mathrm{O}_{2}$ & Orange juice (10 mL) & HRP@chitosan@GO@ $\mathrm{Fe}_{3} \mathrm{O}_{4} @ \mathrm{Pt}$ & $\mathrm{CV}$ & 99 & $\begin{array}{c}48.08 \mu \mathrm{A} \\
/\left(\mu \mathrm{M}(\mathrm{cm})^{2}\right) .\end{array}$ & [75] \\
\hline $\mathrm{Cu}(\mathrm{II})$ & $\begin{array}{c}\text { Oil } \\
(25 \mathrm{~g}), \\
\text { sugar and tea }(10 \mathrm{~g})\end{array}$ & $\mathrm{CoFe}_{2} \mathrm{O}_{4} @ \mathrm{CPE}$ & DP-ASV & 98 & $0.085 \mu \mathrm{g} / \mathrm{L}$ & [16] \\
\hline Tetracycline & $\begin{array}{r}\text { Milk } \\
(15 \mathrm{~g}) \\
\end{array}$ & Ab@carboxyl- $\mathrm{Fe}_{3} \mathrm{O}_{4} @$ chitosan@AuElectrode & DPV & $96-108$ & $0.0321 \mu \mathrm{g} / \mathrm{L}$ & [76] \\
\hline Estradiol & Milk powder (-) & MIP@GSH-Au@Fe $\mathrm{O}_{4} @ G C E$ & DPV & $87-91$ & $2.76 \mathrm{~nm} / \mathrm{L}$ & [77] \\
\hline $\begin{array}{c}\text { Chloramphenicol, } \\
\text { PCB72 }\end{array}$ & $\begin{array}{l}\text { Fish } \\
(5 g)\end{array}$ & Apt (DNA)@QDs@AuNPs@ $\mathrm{Fe}_{2} \mathrm{O}_{4}$ & SWSV & $92-102$ & $0.33-0.35 \mathrm{ng} / \mathrm{L}$ & [79] \\
\hline
\end{tabular}




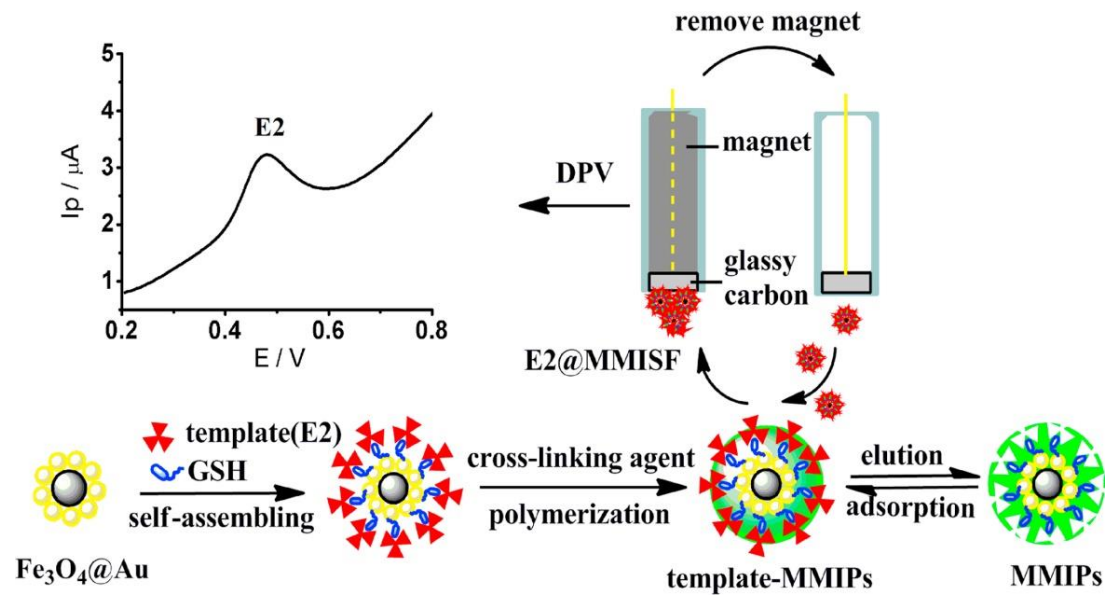

Figure 5. Scheme of a MIP@GSH-Au@ $\mathrm{Fe}_{3} \mathrm{O}_{4} @ G C E$ preparation and differential pulse voltammetry (DPV) measurement performance for the analysis of estradiol in milk powder samples. Reprinted from [77], with permission from Elsevier, 2020.

\subsubsection{Other Types of Sensors}

Apart from the popular optical and electrochemical sensors, other interesting options based on $\mathrm{m}-\mathrm{NPs}$ have been applied for food analysis. The main interest of these alternative sensors lies in the use of a different transduction principles (i.e., quartz crystal microbalance (QCM) [80,81], magnetic relaxation switching (MRS) [82-84], photoelectrochemistry [85,86]) or/and their particular arrangement (i.e., portable and low-cost sensors based on screen-printed electrode (ScPE) [73,85,87-92], lateral flow strip (LFS) [93-96], microfluidic platforms [86,97-99], and smartphone analysis $[95,100,101])$. Some selected examples of these kinds of devices are included in Table $6[80,81,85,86,94,95,98,100,101]$.

QCM sensors are mass-sensitive transducers with a thin plate of quartz attached to gold electrodes. The application of alternate electrical current to the quartz crystal promotes a high-frequency vibration with a resonant frequency. The change in the resonant frequency is linearly related to the change in the mass loaded. This kind of sensor is frequently employed for the detection of viruses and bacteria [102]. Thus, it is not surprising that one of the very few applications in food analysis was devoted to the detection of Campylobacter jejuni in chicken carcasses and ground turkey meat [80]. In that application, bacterial cells were trapped by magnetic nanobeds with a rabbit anti- $C$ jejune $\mathrm{pAb}$ coating. Then, the mouse anti-C. jejuni pAb immobilised on the electrode surface of the sensor bound with magnetic beads and $\mathrm{Au}$ NPs, conjugated with goat anti-rabbit IgG pAb, was introduced into the sensor to amplify the signal via binding the coated magnetic nanobeds. Some important parameters, such as the LOD (20-30 CFU/mL) and detection time (30 min), were determined.

Moreover, the specificity was evaluated by a cross-reactivity test of six non-target foodborne pathogens (Campylobacter coli, Salmonella Typhimurium, Salmonella Enteritidis, Listeria monocytogenes, E. coli and Staphylococcus aureus) and results demonstrated that the inclusion of the Ab-coated magnetic nanobeds increased the specificity and the effective capture and separation of selected bacteria from food matrices. Apart from the analysis of cells, the QMC sensors with m-NPs have also been employed for the direct detection of molecules in food [81]. In this regard, Chen et al. [81] analysed ractopamine (a $\beta$-adrenergic agonist used to treat pulmonary diseases, but also to increase protein deposition and fat mass) in pig fodder samples. For this purpose, amine-functionalised m-NPs were synthesised, functionalised with $\beta$-cyclodextrin and then directly adsorbed onto the surface of the quartz crystal using a magnet. After that, the particles were incubated with the appropriate amount of anti-ractopamine $\mathrm{Ab}$ and a more compact enzyme-linker $\mathrm{Ab}$ conjugate (PowerVision). This sensor provided a LOD of $0.01 \mathrm{ng} / \mathrm{mL}$ with recovery values in the range of $92-110 \%$ and good consistency with ELISA results. 
Table 6. Novel applications of magnetic nanoparticles in other kinds of sensor.

\begin{tabular}{|c|c|c|c|c|c|c|}
\hline Analytes & Matrix & Nanomaterial & $\begin{array}{l}\text { Determination } \\
\text { Technique }\end{array}$ & Recovery \% & LOD & Reference \\
\hline Staphylococcus aureus & $\begin{array}{c}\text { Milk } \\
(1 \mathrm{~mL})\end{array}$ & $\begin{array}{l}\text { Staphylococcus aureus peptide } \\
\text { modified magnetic beads }\end{array}$ & CV, SWSV & 102 & $3 \mathrm{CFU} / \mathrm{mL}$ & [85] \\
\hline $\begin{array}{c}\text { Escherichia coli } \\
\text { O157:H7 }\end{array}$ & $\begin{array}{l}\text { Broth and milk } \\
\quad(1 \mathrm{~mL})\end{array}$ & $\begin{array}{c}\text { Streptavidin-conjugated magnetic } \\
\text { beads }\end{array}$ & $\begin{array}{l}\text { Smartphone } \\
\text { illumination sensor }\end{array}$ & - & $1000 \mathrm{CFU} / \mathrm{mL}$ & [100] \\
\hline $\begin{array}{l}\text { Salmonella } \\
\text { Typhimurium }\end{array}$ & $\begin{array}{l}\text { Chicken } \\
(25 \mathrm{~g})\end{array}$ & $\begin{array}{l}\text { Streptavidin conjugated magnetic } \\
\text { beads@ monoclonal antibodies } \\
\text { against Salmonella Typhimurium }\end{array}$ & $\begin{array}{l}\text { Image software with } \\
\text { smartphone }\end{array}$ & $85-110$ & $16 \mathrm{CFU} / \mathrm{mL}$ & {$[101]$} \\
\hline 3 Antibiotics & $\begin{array}{c}\text { Milk } \\
(-)\end{array}$ & $\begin{array}{l}\text { Polystyrenebeads@m-NPs } \\
\text { (carboxylc acid and amine } \\
\text { functionalized with sizes between } 30 \\
\text { and } 1000 \mathrm{~nm} \text { ) }\end{array}$ & NMR & $96-120$ & $8.5 \mathrm{pg} / \mathrm{mL}-0.5 \mathrm{ng} / \mathrm{mL}$ & [82] \\
\hline Campylobacter jejuni & $\begin{array}{l}\text { Pure culture, chicken } \\
\text { carcasses and ground } \\
\text { turkey meat } \\
\quad(25 \mathrm{~g})\end{array}$ & $\begin{array}{c}\text { Magnetic nanobeds coated with } \\
\text { rabbit anti-C. jejuni polyclonal } \\
\text { antibody and AuNPs conjugated } \\
\text { with goat anti-rabbit } \\
\text { immunoglobulin G polyclonal } \\
\text { antibody }\end{array}$ & QMC & - & 20-30 CFU/mL & [80] \\
\hline$\beta$-coglutin & $\begin{array}{c}\text { Lupine } \\
(-)\end{array}$ & $\mathrm{Fe}_{3} \mathrm{O}_{4} @ \mathrm{Au}$ core-shell & $\begin{array}{l}\text { Image software with } \\
\text { smartphone }\end{array}$ & - & $8 \mathrm{fM}$ & [95] \\
\hline Aflatoxin $B_{1}$ & $\begin{array}{l}\text { Peanut } \\
(5 \mathrm{~g})\end{array}$ & $\begin{array}{c}\text { Anti-aflatoxin } \mathrm{B}_{1} \text { antibody-modified } \\
\text { magnetic beads and carbon quantum } \\
\text { dots functionalized } \mathrm{MnO}_{2} \\
\text { nanosheets }\end{array}$ & Photoelectrochemical & - & $2.1 \mathrm{pg} / \mathrm{mL}$ & [86] \\
\hline Ractopamine & $\begin{array}{l}\text { Pig fodder } \\
\quad(1 \mathrm{~g})\end{array}$ & $\mathrm{Fe}_{3} \mathrm{O}_{4} @ \beta-\mathrm{CD}$ & QMC & $91-110$ & $0.01 \mathrm{ng} / \mathrm{mL}$ & [81] \\
\hline $\begin{array}{c}\text { Altenariol } \\
\text { monomethyl ether }\end{array}$ & $\begin{array}{l}\text { Apple, cherry and orange } \\
(5 \mathrm{~g})\end{array}$ & $\begin{array}{c}\mathrm{Fe}_{3} \mathrm{O}_{4} @ \mathrm{BSA} \text {-altenariol monomethyl } \\
\text { ether - }\end{array}$ & $\begin{array}{l}\text { UV Image software } \\
\text { with smartphone }\end{array}$ & $91-94$ & $7 \mathrm{pg} / \mathrm{mL}$ & [98] \\
\hline
\end{tabular}


MRS sensors in combination with m-NPs have also been employed for the analysis of food samples [82-84]. The sensor is based on the change in the spin-spin relaxation time produced on the surrounding water molecules as a result of the modifications on the dispersed and aggregate states of m-NPs when an analyte appears in the magnetic field. The changes of spin-spin relaxation time depend on the amount of the target compound in the sample. These changes are measured through nuclear magnetic resonance (NMR). Among the applications in food analysis, the determination of bacterial populations is frequent $[83,84]$, although organic individual compounds such as antibiotics (i.e., chloramphenicol, sulfonamide and oxytetracycline) have been also studied [82]. For example, Xianyu et al. [82] developed a biosensor for analysing three antibiotics belonging to different families (amphenicols, sulphonamides and tetracyclines) in milk. For this purpose, they developed a method based on click chemistry to assemble different sizes of polystyrene beads and magnetic nanoparticles to prepare core-satellite structures that enable the MRS assays. The click chemistry-mediated MRS was compared with traditional MRS. The LOQs obtained with the click-mediated sensor $(8.5 \mathrm{pg} / \mathrm{mL}$ for chloramphenicol and $0.5 \mathrm{ng} / \mathrm{mL}$ for sulfonamide) were between 72 and 100 times better. The selectivity using antibiotic analogues (thiamphenicol, cephalosporin, tetracycline, sulfadimidine and gentamicin) for detection of chloramphenicol was tested and results showed that only the target compound produced an appreciable effect on the magnetic signal. As can be deduced, the analysis of antibiotics using m-NPs is an important topic [103]. Thus, it is expected that the number of publications within food analysis in this regard will increase in the next few years.

Regarding the transduction principle, it is also worth mentioning the so-called photoelectrochemical sensors $[85,86]$. Photoelectrochemical sensing is based on the use of light as the excitation source and photocurrent generated on the electrode as the detection signal. This combination joins the advantages of both methods. These sensors are inherently sensitive with a low background signal and a fast response. Moreover, the system is simple, easily miniaturised, consumes low energy, and has a low cost. As an example, Lin et al. [86] developed a photoelectrochemical immunoassay for the detection of aflatoxin $B_{1}$ in peanut samples. With this aim, anti-aflatoxin $B_{1} A b$-modified magnetic beads were used as support for the immunoreaction, glucose oxidase labeled aflatoxin $\mathrm{B}_{1}$-BSA conjugates as the tag with competitive immunoassay format and carbon QDs functionalised $\mathrm{MnO}_{2}$ nanosheets for the visual and photoelectrochemical evaluation. After the modification of the electrode surface with carbon QDs functionalised $\mathrm{MnO}_{2}$, the anti-aflatoxin $\mathrm{B}_{1} \mathrm{Ab}$-modified magnetic beads were flowed through the detection cell and collected on the electrode with a magnet. Then, the sample extract and the glucose oxidase labeled aflatoxin $\mathrm{B}_{1}$-BSA conjugates were injected simultaneously and reacted for $60 \mathrm{~min}$ to complete the competitive-type immunoreaction. After that, the glucose substrate was flowed and reacted for $15 \mathrm{~min}$. The formation of immunecomplexes involves the oxidation of glucose generating $\mathrm{H}_{2} \mathrm{O}_{2}$ (which reduced $\mathrm{MnO}_{2}$ to $\mathrm{Mn}(\mathrm{II})$ ). In this way, the QDs are dissociated from the electrode and the photocurrent is reduced. The obtained sensor showed a LOD of $2.1 \mathrm{pg} / \mathrm{mL}$ with good reproducibility (RSDs in the range 4.3-10.7\%) and acceptable accuracy. The method was compared with ELISA and both techniques provided similar results.

The use of low-cost and portable platforms for sensor operations has attracted growing interest since no expensive and easy-to-handle devices are required [1]. It should be mentioned that the different sensors described in this part are based on the detection options previously described. However, due to their particular arrangement and interesting advantages, a separate description is included here. Among the different strategies, the use of ScPE in combination with m-NPs has been the most popular for the analysis of food [73,83,87-92]. ScPEs are planar systems with the three electrodes of the electrochemical cell arranged on a plastic, ceramic, textile or paper substrate. The minimal sample consumption of these devices, together with other advantages such as a mass-scale production, simplicity, selectivity, disposable use and flexibility, justifies their popularity [104]. In combination with m-NPs, ScPE has been used for the analysis of allergens [73], $\beta$-agonists [87], mycotoxins [92], bacteria [88], pesticides [89,90], polybrominated diphenyl ethers [91], and biogenic amines in seafood [73], meat [87,91], cereals [92], beverages [88,89], vegetables [90], milk [91], fish [91] 
and eggs [91]. For this purpose, functionalised m-NPs are coated with a suitable substrate and trapped at the ScPE surface with a magnet at the backside.

LFS is a rapid, portable, simple and inexpensive system based on separation at strips as a result of the sample flow produced by capillary action. For this purpose, samples are deposited at the initial sample pad and, after flowing to the adsorbent pad through the strip, the signal is measured. Frequently, such separation is provided by an immunechromatographic phenomenon on specific molecules immobilised on two lines (control and analysis). However, sometimes this system can be less sensitive than other methods. This may be why not many LFS assays are commercially available. This kind of sensor has been employed together with m-NPs to analyse biogenic amines [93], oestrogenic compounds [94], globulin proteins [95] and botulinum neurotoxins [96] in beverages [93,96], milk [94,96], fish [94], meat [94] and legumes [95]. The main advantage of the introduction of m-NPs is the drastic increase in sensitivity and reduction of the LOD. In this regard, Wu et al. [95] applied three different LFS sensors (a conventional method, a sensitised system and a magnetically immobilised Apt (Figure 6)) for the detection of $\beta$-coglutin in lupine. In the classical version, the analyte was placed on the sample pad and flowed longitudinally by capillary action. The strip-immobilised Apt formed a sandwich-type immunocomplex (Apt-antigen-Apt) as analytes conjugated with AuNPs-secondary Apt. The detection was based on the colour developed by the AuNPs in the test zone (Figure 6a). In order to increase the detectability of Au-NPs, the sensitised probe was modified with HRP. The addition of 3,3',5,5' -tetramethylbenzidine allows a quick reaction with HRP creating a blue enhanced signal (Figure 6b). Finally, the inclusion of a magnet under the strip to trap the $\mathrm{Fe}_{3} \mathrm{O}_{4} @ \mathrm{Au}$ core-shell NPs allowed an increase in the amount of analyte conjugated with the immobilised Apt (Figure 6c). The combination of magnetic concentration with enzyme amplification (through HRP) increased detection sensitivity by more than 1000 times (LOD $8 \mathrm{fM}$ ). Cross-reactivity with $\alpha, \gamma$, and $\delta$ lupin coglutins was tested and significant changes were not detected with these coglutins.

Microfluidic platforms integrate separation, identification and determination in microfluidic channels in a compacted, flexible and modular format. Moreover, its combination with magnetic NPs allows benefiting from the advantages of these materials. Thus, it is not surprising that microfluidic chips using immunomagnetic separation [97,98], electrochemical, magnetic [99] or optical detection [98], have been developed. In these applications, the microfluidic chips were fabricated according to the particular needs and were mainly applied for the analysis of bacteria $[97,99]$, although organic compounds (such as mycotoxins [98]) were also analysed.

Finally, regarding the use of sensors, their combination with smartphones should be highlighted $[95,100,101]$. That combination takes portability to another level involving a device that the vast majority of the population carries every day. Moreover, these devices are equipped with high-resolution cameras, potent processors, and allow wireless communication. Their use does not require extra and expensive instruments and most people are familiar with the management of apps. Although some applications are limited when using the smartphone as the analyser $[95,101]$ through image-processing software, some innovative applications go beyond this. In this regard, Park et al. [100] developed a methodology that employed the smartphone in different steps of the analytical process. For evaluation of DNA amplicons in broth and milk, avidin-conjugated magnetic NPs and succinimide-linked sepharose were used with biotin primers. A portable low-power fan was modified for its use as a portable rotor and connected to the charging port of the smartphone. In this way, the centrifugal-based affinity ligand chromatography was performed. The change in distance produced during centrifugation as a result of the binding variation of NPs with DNA amplicons was optically measured using the illumination sensor of the smartphone with respect to the altered transmittance caused by the magnetic material. Thus, the detection by the naked eye acts as quick polymerase chain reaction (PCR) screening. 
a

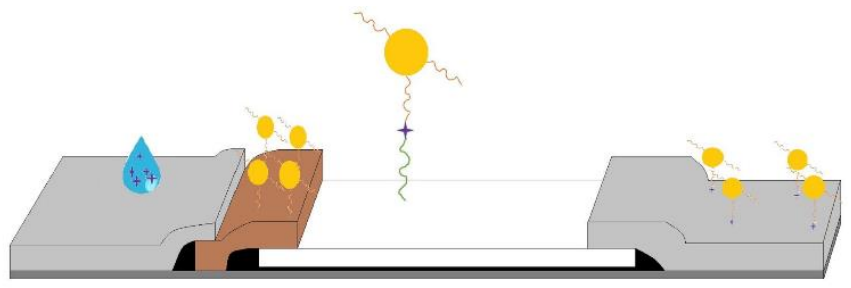

b

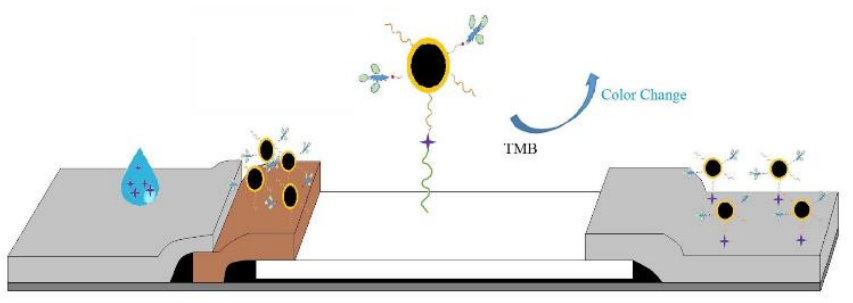

c
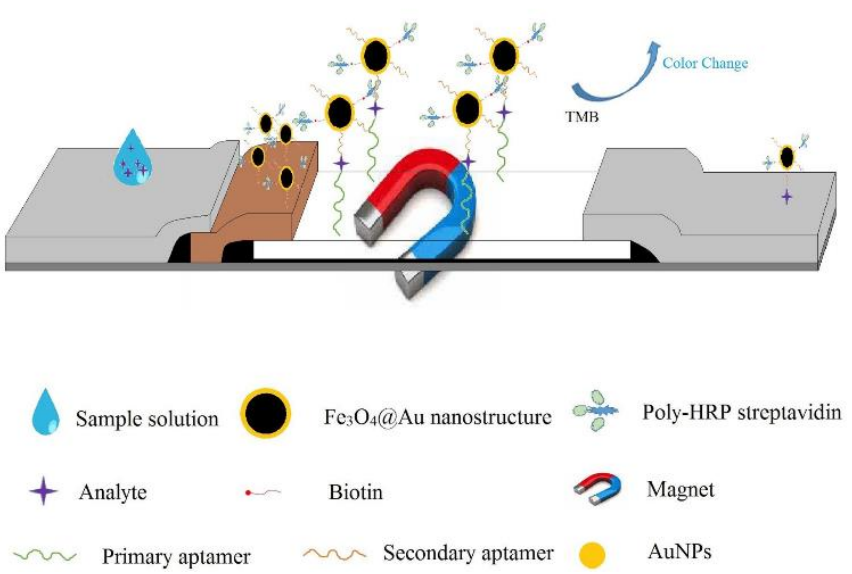

Figure 6. Schematic illustration of the principles of the traditional AuNPs-based lateral flow immunochromatographic assay method (a) the enzyme signal amplification-based based lateral flow immunechromatographic method (b) and the $\mathrm{Fe}_{3} \mathrm{O}_{4} @ \mathrm{Au}$ NPs based lateral flow immunechromatographic method assisted with enzyme amplification and external magnetic field (c). Reprinted from [95] with permission from Elsevier, 2020.

\section{Conclusions and Remarks about the Future}

Food analysis is a topic of great concern and has a big impact on food systems and policies of countries around the world. The control of possible contaminants and naturally present compounds is essential. Current research in food science is intended to ensure a suitable detection of these molecules at extremely low concentrations in complicated matrices. For this reason, the development of sensitive advanced methodologies plays a predominant role in analytical chemistry research. Nanotechnology has arisen as an alternative for achieving this aim. In this regard, different NPs have been synthesised to overcome the problems of classical extraction methods. Among them, m-NPs have attracted great attention thanks to their interesting chemical, optical and magnetic properties, such as the easy isolation by magnets, simple functionalisation and/or coating, superparamagnetism, etc. The continuously growing number of publications centred on the synthesis and application of m-NPs suggest that interest in new magnetic particles continues. The practically unlimited possibilities for covalent or non-covalent modifications with high simplicity and relatively low cost ensure the synthesis of the suitable m-NPs for a particular application. In fact, several companies sell already-prepared m-NPs for analytical purposes. Thus, research on this topic is guaranteed within the next years. 
The use of m-NPs has allowed the introduction of efficient sample extraction protocols and facilitated the application of the already well-known ones. Their extraordinarily high surface-area-to-volume ratio and their relatively easy functionalisation (which results in more selective sorbents) have propitiated this use. Different types of nanocomposite based on m-NPs have been applied. Carbonaceous modified NPs (including graphene and CNTs), MOF-based composites, polymeric modifications and surface functionalisation attachments have been reported in the literature. Moreover, combinations of two or more of these materials have become very popular, providing good recovery with simple, fast and more environmentally friendly processes. Moreover, cost and solvent consumption have been considerably reduced.

The particular electrical and magnetic properties of m-NPs make them exceptional transducers. For this reason, their use as substrates for building sensors has skyrocketed within food science. This kind of materials allowed the development of high throughput, real-time and portable detection methods. In this regard, the production of low-cost and portable sensors based on ScPE, LFS, microfluidic platforms and smartphone analysis implies a new paradigm. Such devices combine simplicity, rapidity and practicality while expensive instruments and complicated pre-treatment methodologies are not required. However, it should be mentioned that some challenges could be associated with the use of sensors in food analysis: sensitivity and repeatability depend on the sample preparation method and short shelf life reduces the detection efficiency.

The employment of miniaturised devices based on m-NPs is expected to increase in the next few years to develop highly efficient analytical systems with fast and accurate methodologies for sample preparation and analysis.

Finally, it should be noted that, from a green chemistry perspective, the analytical procedures involving m-NPs usually comprise short analysis time and a limited number of steps and require lower amounts of a sorbent that can be re-used without a significant loss in efficiency. Moreover, the volumes of loading and elution solvents are frequently reduced. However, the material preparation usually employs contaminant substances and/or generates harmful wastes. Furthermore, the recyclability of $\mathrm{m}-\mathrm{NPs}$ is not always ensured. Thus, further profound studies are needed to ensure that m-NP-based methodologies are consistent with green chemistry principles.

Author Contributions: All the authors contributed to the bibliographic research, writing and reviewing the manuscript. B.S.R. envisioned the review. All authors have read and agreed to the published version of the manuscript.

Funding: This work was supported by the Spanish Ministry of Economy and Competitiveness (project AGL2017-89257-P).

Conflicts of Interest: The authors declare no conflict of interest.

\section{Abbreviations}

3-CPTS: 3-(chloropropyl)trimethoxysilane; 3Dgraphene: three-dimensional graphene; 4-bpmb: N,N-Bis[1(pyridine-2-yl)ethylene]-benzene-1,4-diamine); 4-nbpy: bis-pyridin-4-ylmethylene -naphtalene-1,5-diamine; Ab: antibody; ABEI: N-(aminobutyl)-N-(ethylisoluminol); ABTS: 2'-azino-bis(3-ethylbenzothiazoline-6-sulfonic acid); ACN: acetonitrile; Apt: aptamer; APTES: (3-aminopropyl) triethoxysilane; ATP: attapulgite; AuNF: functionalised flowerlike gold nanoparticle; $\beta$-CD: $\beta$-cyclodextrin; Bd: bencidine; BDC: terephthalic acid; BoNT/A: botulinum neurotoxin type A; BSA: bovine serum albumin; $C_{18}$ octadecylsilane; $C$ dna: conjugated DNA; CE: capillary electrophoresis; CFU: colony forming unit; CNT: carbon nanotube; COOH-MWCNT: carboxylated multi-walled carbon nanotubes; CPE: carbon paste electrode; CRM: certified reference material; CSA-1-Ab: Salmonella structural antigen; CV: cyclic voltammetry; DAD: diode array detection; DCM: dichloromethane; DEG: diethylene glycol; DMF: dimethylformamide; DMSO: dimethyl sulfoxide; DP-ASV: differential pulse anodic stripping voltammetry; DPV: differential pulse voltammetry; DSN: 5,5'-dithiobis(succinimidyl-2-nitrobenzoate); DTIM: 4-(5)-imidazoledithiocarboxylic acid; DTNB: 5,5'-dithiobis (2-nitrobenzoic acid); DVB: divinylbenzene; EDS: (1-ethyl-3-(3-dimethylaminopropyl) carbodiimide; EG: ethylene glycol; EHA: 2-ethylhexylacrylate; EIS: electrochemical impedance spectroscopy; ELISA: enzyme-linked immunosorbent assay; ET-AAS: electrothermal atomic absorption spectroscopy; EtOH: ethanol; FAA: flame atomic absorption spectroscopy; FD: fluorescence detection; FP-m-NP: functionalised polymeric magnetic nanoparticle; FTIR: Fourier-transform infrared spectroscopy; GC: gas chromatography; GCB: graphitized carbon black; GCE: glassy carbon electrode; GNT: gold nanotriangle; GO: graphene oxide; GSH: glutathione; $\mathrm{H}_{2} \mathrm{BDC}$ : benzene 1,4-dicarboxylic acid; $\mathrm{H}_{2} \mathrm{Oba}$ : 4,4'-oxybis(benzoic acid); HLB: hydrophilic-lipophilic balance; HPLC: high-performance liquid chromatography; 
HRP: horseradish peroxidase; IgG: immunoglobulin G, IIP: ion-imprinted polymer; IL: ionic liquid; IR: infrared spectroscopy; LFA: lateral flow assay; LFIA: lateral flow immunoassay; LFS: lateral flow strip; LLE: liquid-liquid extraction; LOD: limit of detection; $\mathrm{m}-\mu$-dSPE: magnetic-micro-dispersive solid-phase extraction; MAA: methylacrylic acid; mAb: monoclonal antibody; MAE: microwave assisted extraction; MECLIA: magnetic enzyme chemiluminescence immunoassay; $\mathrm{MeOH}$ : methanol; m-FC: magnetic framework composite; MIP: molecularly imprinted polymer; MMA: methyl methacrylate; m-MHSPE: mixed hemimicelles solid-phase extraction; m-MOF: magnetic-metal-organic framework; m-NP: magnetic nanoparticle; MOF: metal-organic framework; m-QD: magnetic-quantum dot; MRS: magnetic relaxation switching; MS: mass spectrometry; MS/MS: tandem mass spectrometry; m-SCSE: magnetic-stir cake sorptive extraction; MWCNT: multi-walled carbon nanotube: ND: nanodiamon; NF: nanofiber; NH: nanohorn; NHS: n-hydroxyl succinimide; NIP: non-imprinted polymer; NMR: nuclear magnetic resonance; NP: nanoparticle; pAb: polyclonal antibody; PAE: phthalic acid ester; PAN: 1-(2-pyridylazo)-2-naphthol; PBS: phosphate buffered saline; PCB72: polychlorinated biphenyl-72; PCR: polymerase chain reaction; pDA: polydopamine; PEDOT: poly(3,4-ethylenedioxythiophene); PEI: polyethyleneimine; PIP: $p$-iodophenol; PolyHIPE: polymerised high internal phase emulsion; PSA: primary-secondary amine; PVP: polyvinylpyrrolidone; Q: single quadrupole; QCM: quartz crystal microbalance; QD: quantum dot; QqQ: triple quadrupole; QuEChERS: quick, easy, cheap, effective, rugged, safe; r-GO: reduced-graphene oxide; RR: event-specific roundup ready; SBSE: stir bar sorption extraction; ScPE: screen-printed electrode; SEB: staphylococcal enterotoxin; SEM: scanning electron microscopy; SERS: surface-enhanced Raman spectroscopy; SLE: solid-liquid extraction; SPE: solid-phase extraction; SPR: surface plasmon resonance; SWSV: square wave stripping voltammetry; Tb: 1,3,5-triformylbenzene; TEA: triethylamine; TEAS: tetraethyl orthosilicate; TEM: transmission electron microscopy; TGA: thermal gravimetric analysis; ThGA: thioglycolic acid; Tol: p-Tolyl isocyanates; UA: ultrasound assisted; UAE: ultrasound assisted extraction; UCNP: lanthanide-doped upconversion nanoparticle; UHPLC: ultra-high performance liquid chromatography; UV: ultraviolet; VA: vortex assisted; VA-m- $\mu$-dSPE: vortex assisted-magnetic-micro-dispersive solid-phase extraction; VSM: vibrating-sample magnetometry; XRD: X-ray powder diffraction.

\section{References}

1. Li, Y.; Wang, Z.; Sun, L.; Liu, L.; Xu, C.; Kuang, H. Nanoparticle-based sensors for food contaminants. TrAC Trends Anal. Chem. 2019, 113, 74-83. [CrossRef]

2. V. Soares Maciel, E.; de Toffoli, A.L.; Lanças, F.M. Recent trends in sorption-based sample preparation and liquid chromatography techniques for food analysis. Electrophoresis 2018, 39, 1582-1596. [CrossRef] [PubMed]

3. Krishna, V.D.; Wu, K.; Su, D.; Cheeran, M.C.J.; Wang, J.P.; Perez, A. Nanotechnology: Review of concepts and potential application of sensing platforms in food safety. Food Microbiol. 2018, 75, 47-54. [CrossRef] [PubMed]

4. Socas-Rodríguez, B.; González-Sálamo, J.; Hernández-Borges, J.; Rodríguez-Delgado, M.Á. Recent applications of nanomaterials in food safety. TrAC Trends Anal. Chem. 2017, 96, 172-200. [CrossRef]

5. González-Sálamo, J.; Socas-Rodríguez, B.; Hernández-Borges, J.; Rodríguez-Delgado, M.Á. Nanomaterials as sorbents for food sample analysis. TrAC Trends Anal. Chem. 2016, 85, 203-220. [CrossRef]

6. Reinholds, I.; Jansons, M.; Pugajeva, I.; Bartkevics, V. Recent Applications of Carbonaceous Nanosorbents in Solid Phase Extraction for the Determination of Pesticides in Food Samples. Crit. Rev. Anal. Chem. 2019, 49, 439-458. [CrossRef]

7. Khan, R.; Rehman, A.; Hayat, A.; Andreescu, S. Magnetic Particles-Based Analytical Platforms for Food Safety Monitoring. Magnetochemistry 2019, 5, 63. [CrossRef]

8. Hernández-Hernández, A.A.; Álvarez-Romero, G.A.; Contreras-López, E.; Aguilar-Arteaga, K.; Castañeda-Ovando, A. Food Analysis by Microextraction Methods Based on the Use of Magnetic Nanoparticles as Supports: Recent Advances. Food Anal. Methods 2017, 10, 2974-2993. [CrossRef]

9. Kepekci Tekkeli, S..E.; Durmus, Z. Magnetic solid phase extraction applications combined with analytical methods for determination of drugs in different matrices review. J. Chil. Chem. Soc. 2019, 64, 4448-4458. [CrossRef]

10. Huang, Z.; Hu, S.; Xiong, Y.; Wei, H.; Xu, H.; Duan, H.; Lai, W. Application and development of superparamagnetic nanoparticles in sample pretreatment and immunochromatographic assay. TrAC Trends Anal. Chem. 2019, 114, 151-170. [CrossRef]

11. Tolmacheva, V.V.; Apyari, V.V.; Kochuk, E.V.; Dmitrienko, S.G. Magnetic adsorbents based on iron oxide nanoparticles for the extraction and preconcentration of organic compounds. J. Anal. Chem. 2016, 71, 321-338. [CrossRef] 
12. Matta, L.L.; Alocilja, E.C. Emerging nano-biosensing with suspended MNP microbial extraction and EANP labeling. Biosens. Bioelectron. 2018, 117, 781-793. [CrossRef] [PubMed]

13. Karami-Osboo, R.; Miri, R.; Javidnia, K.; Shojaee, M.H.; Kobarfard, F. Extraction and determination of sulfadiazine and sulfathiazole in milk using magnetic solid phase extraction-HPLC-UV. Anal. Methods 2015, 7, 1586-1589. [CrossRef]

14. Zhang, J.; Shao, J.; Guo, P.; Huang, Y. A simple and fast $\mathrm{Fe}_{3} \mathrm{O}_{4}$ magnetic nanoparticles-based dispersion solid phase extraction of Sudan dyes from food and water samples coupled with high-performance liquid chromatography. Anal. Methods 2013, 5, 2503-2510. [CrossRef]

15. Yáñez-Sedeño, P.; Campuzano, S.; Pingarrón, J.M. Electrochemical sensors based on magnetic molecularly imprinted polymers: A review. Anal. Chim. Acta 2017, 960, 1-17. [CrossRef] [PubMed]

16. Mohamed, M.A.; El-Badawy, F.M.; El-Desoky, H.S.; Ghoneim, M.M. Magnetic cobalt ferrite nanoparticles $\mathrm{CoFe}_{2} \mathrm{O}_{4}$ platform as an efficient sensor for trace determination of $\mathrm{Cu}(\mathrm{II})$ in water samples and different food products. New J. Chem. 2017, 41, 11138-11147. [CrossRef]

17. Santana-Mayor, Á; Rodríguez-Ramos, R.; Socas-Rodríguez, B.; Asensio-Ramos, M.; Rodríguez-Delgado, M. Carbon-based adsorbents. In Solid-Phase Extraction Handbooks in Separation Science; Poole, C.F., Ed.; Elsevier: Amsterdam, The Netherlands, 2020; pp. 83-128. ISBN 978-0-12-816906-3.

18. Ulusoy, H.I.; Gülle, S.; Yilmaz, E.; Soylak, M. Trace determination of vitamin B12 in food samples by using $\mathrm{Fe}_{3} \mathrm{O}_{4}$ magnetic particles including multi-walled carbon nanotubes and nanodiamonds. Anal. Methods 2019, 11, 5108-5117. [CrossRef]

19. Fu, L.; Zhou, H.; Miao, E.; Lu, S.; Jing, S.; Hu, Y.; Wei, L.; Zhan, J.; Wu, M. Functionalization of amino terminated carbon nanotubes with isocyanates for magnetic solid phase extraction of sulfonamides from milk and their subsequent determination by liquid chromatography-high resolution mass spectrometry. Food Chem. 2019, 289, 701-707. [CrossRef]

20. Sereshti, H.; Khodayari, F.; Nouri, N. Simultaneous Determination of Aflatoxins in Bread by In-Syringe Dispersive Micro-Solid Phase Extraction Using Magnetic Three-Dimensional Graphene Followed by HPLC-FLD. Food Anal. Methods 2019, 12, 2273-2281. [CrossRef]

21. Moazzen, M.; Mousavi Khaneghah, A.; Shariatifar, N.; Ahmadloo, M.; Eş, I.; Baghani, A.N.; Yousefinejad, S.; Alimohammadi, M.; Azari, A.; Dobaradaran, S.; et al. Multi-walled carbon nanotubes modified with iron oxide and silver nanoparticles (MWCNT-Fe $\mathrm{O}_{4} / \mathrm{Ag}$ ) as a novel adsorbent for determining PAEs in carbonated soft drinks using magnetic SPE-GC/MS method. Arab. J. Chem. 2019, 12, 476-488. [CrossRef]

22. Ma, S.; Wang, M.; You, T.; Wang, K. Using Magnetic Multiwalled Carbon Nanotubes as Modified QuEChERS Adsorbent for Simultaneous Determination of Multiple Mycotoxins in Grains by UPLC-MS/MS. J. Agric. Food Chem. 2019, 67, 8035-8044. [CrossRef] [PubMed]

23. Kılınç, E.; Çelik, K.S.; Bilgetekin, H. $\gamma$ - $\mathrm{Fe}_{2} \mathrm{O}_{3}$ magnetic nanoparticle functionalized with carboxylated multi walled carbon nanotube for magnetic solid phase extractions and determinations of Sudan dyes and Para Red in food samples. Food Chem. 2018, 242, 533-537. [CrossRef] [PubMed]

24. Wu, L.; Yu, L.; Ding, X.; Li, P.; Dai, X.; Chen, X.; Zhou, H.; Bai, Y.; Ding, J. Magnetic solid-phase extraction based on graphene oxide for the determination of lignans in sesame oil. Food Chem. 2017, 217, 320-325. [CrossRef] [PubMed]

25. Tavakoli, M.; Hajimahmoodi, M.; Shemirani, F.; Dezfuli, A.S.; Khanavi, M. Application of Fe3O4/RGO Nanocomposite as a Sorbent of Pesticides. Chromatographia 2017, 80, 1423-1432. [CrossRef]

26. Capriotti, A.L.; Cavaliere, C.; Foglia, P.; La Barbera, G.; Samperi, R.; Ventura, S.; Laganà, A. Mycoestrogen determination in cow milk: Magnetic solid-phase extraction followed by liquid chromatography and tandem mass spectrometry analysis. J. Sep. Sci. 2016, 39, 4794-4804. [CrossRef]

27. Li, Z.; Li, Y.; Qi, M.; Zhong, S.; Wang, W.; Wang, A.J.; Chen, J. Graphene-Fe ${ }_{3} \mathrm{O}_{4}$ as a magnetic solid-phase extraction sorbent coupled to capillary electrophoresis for the determination of sulfonamides in milk. J. Sep. Sci. 2016, 39, 3818-3826. [CrossRef]

28. Sierra, I.; Morante-Zarcero, S. New Advances in Food Sample Preparation with Nanomaterials for Organic Contaminants Analysis by Liquid Chromatography; Elsevier Inc.: Amsterdam, The Netherlands, 2018; ISBN 9780128127926.

29. Xiao, R.; Zhang, X.; Zhang, X.; Niu, J.; Lu, M.; Liu, X.; Cai, Z. Analysis of flavors and fragrances by HPLC with Fe3O4@GO magnetic nanocomposite as the adsorbent. Talanta 2017, 166, 262-267. [CrossRef] 
30. Mahpishanian, S.; Sereshti, H. Three-dimensional graphene aerogel-supported iron oxide nanoparticles as an efficient adsorbent for magnetic solid phase extraction of organophosphorus pesticide residues in fruit juices followed by gas chromatographic determination. J. Chromatogr. A 2016, 1443, 43-53. [CrossRef]

31. Wang, P.L.; Xie, L.H.; Joseph, E.A.; Li, J.R.; Su, X.O.; Zhou, H.C. Metal-Organic Frameworks for Food Safety. Chem. Rev. 2019, 119, 10638-10690. [CrossRef]

32. Manousi, N.; Giannakoudakis, D.A.; Rosenberg, E.; Zachariadis, G.A. Extraction of metal ions with metal-organic frameworks. Molecules 2019, 24, 4605. [CrossRef]

33. Durmus, Z.; Kurt, B.Z.; Gazioğlu, I.; Sevgi, E.; Hancer, C.K. Spectrofluorimetric Determination of Aflatoxin B 1 in Winter Herbal Teas via Magnetic Solid Phase Extraction Method by using Metal—Organic Framework (MOF) Hybrid Structures Anchored with Magnetic Nanoparticles. Appl. Organomet. Chem. 2020, 34, e5375. [CrossRef]

34. Shi, X.; Chen, X.; Hao, Y.; Li, L.; Xu, H.; Wang, M. Magnetic metal-organic frameworks for fast and efficient solid-phase extraction of six Sudan dyes in tomato sauce. J. Chromatogr. B 2018, 1086, 146-152. [CrossRef] [PubMed]

35. Yamini, Y.; Safari, M. Magnetic Zink-based metal organic framework as advance and recyclable adsorbent for the extraction of trace pyrethroids. Microchem. J. 2019, 146, 134-141. [CrossRef]

36. Shakourian, M.; Yamini, Y.; Safari, M. Facile magnetization of metal-Organic framework TMU-6 for magnetic solid-phase extraction of organophosphorus pesticides in water and rice samples. Talanta 2020, 218, 121139. [CrossRef]

37. Liu, J.; Li, G.; Wu, D.; Yu, Y.; Chen, J.; Wu, Y. Facile preparation of magnetic covalent organic framework-metal organic framework composite materials as effective adsorbents for the extraction and determination of sedatives by high-performance liquid chromatography/tandem mass spectrometry in meat samp. Rapid Commun. Mass Spectrom. 2020, 34, e8742. [CrossRef]

38. Niu, M.; Li, Z.; He, W.; Zhou, W.; Lu, R.; Li, J.; Gao, H.; Zhang, S.; Pan, C. Attapulgite modified magnetic metal-organic frameworks for magnetic solid phase extraction and determinations of benzoylurea insecticides in tea infusions. Food Chem. 2020, 317, 126425. [CrossRef]

39. Tadjarodi, A.; Abbaszadeh, A. A magnetic nanocomposite prepared from chelator-modified magnetite $\left(\mathrm{Fe}_{3} \mathrm{O}_{4}\right)$ and HKUST-1 (MOF-199) for separation and preconcentration of mercury(II). Microchim. Acta 2016, 183, 1391-1399. [CrossRef]

40. Esmaeilzadeh, M. Ultrasound-assisted dispersive magnetic solid phase extraction based on metal-organic framework/1-(2-pyridylazo)-2-naphthol modified magnetite nanoparticle composites for speciation analysis of inorganic tin. New J. Chem. 2019, 43, 4929-4936. [CrossRef]

41. Senosy, I.A.; Guo, H.M.; Ouyang, M.N.; Lu, Z.H.; Yang, Z.H.; Li, J.H. Magnetic solid-phase extraction based on nano-zeolite imidazolate framework-8-functionalized magnetic graphene oxide for the quantification of residual fungicides in water, honey and fruit juices. Food Chem. 2020, 325, 126944. [CrossRef]

42. Du, F.; Sun, L.; Tan, W.; Wei, Z.; Nie, H.; Huang, Z.; Ruan, G.; Li, J. Magnetic stir cake sorptive extraction of trace tetracycline antibiotics in food samples: Preparation of metal-organic framework-embedded polyHIPE monolithic composites, validation and application. Anal. Bioanal. Chem. 2019, 411, 2239-2248. [CrossRef]

43. Bagheri, A.R.; Ghaedi, M. Magnetic metal organic framework for pre-concentration of ampicillin from cow milk samples. J. Pharm. Anal. 2020. [CrossRef]

44. Gao, Y.; Liu, G.; Gao, M.; Huang, X.; Xu, D. Recent Advances and Applications of Magnetic Metal-Organic Frameworks in Adsorption and Enrichment Removal of Food and Environmental Pollutants. Crit. Rev. Anal. Chem. 2019, 1-13. [CrossRef] [PubMed]

45. Zou, J.; Peng, Y.G.; Tang, Y.Y. A facile bi-phase synthesis of Fe3O4@SiO2 core-shell nanoparticles with tunable film thicknesses. RSC Adv. 2014, 4, 9693-9700. [CrossRef]

46. González-Sálamo, J.; Herrera-Herrera, A.V.; Fanali, C.; Hernández-Borges, J. Magnetic nanoparticles for solid-phase extraction. LCGC Eur. 2016, 29, 180-193.

47. Faraji, M.; Yamini, Y.; Rezaee, M. Magnetic nanoparticles: Synthesis, stabilization, functionalization, characterization, and applications. J. Iran. Chem. Soc. 2010, 7, 1-37. [CrossRef]

48. Zhang, C.; Shi, X.; Yu, F.; Quan, Y. Preparation of dummy molecularly imprinted polymers based on dextran-modified magnetic nanoparticles $\mathrm{Fe} 3 \mathrm{O} 4$ for the selective detection of acrylamide in potato chips. Food Chem. 2020, 317, 126431. [CrossRef] [PubMed] 
49. Lei, H.; Hu, Y.; Li, G. Magnetic poly(phenylene ethynylene) conjugated microporous polymer microspheres for bactericides enrichment and analysis by ultra-high performance liquid chromatography-tandem mass spectrometry. J. Chromatogr. A 2018, 1580, 22-29. [CrossRef]

50. Wu, L.; Lin, Z.Z.; Zeng, J.; Zhong, H.P.; Chen, X.M.; Huang, Z.Y. Detection of malachite green in fish based on magnetic fluorescent probe of CdTe QDs/nano-Fe3O4@MIPs. Spectrochim. Acta Part. A Mol. Biomol. Spectrosc. 2018, 196, 117-122. [CrossRef]

51. Socas-Rodríguez, B.; Hernández-Borges, J.; Herrera-Herrera, A.V.; Rodríguez-Delgado, M.Á. Multiresidue analysis of oestrogenic compounds in cow, goat, sheep and human milk using core-shell polydopamine coated magnetic nanoparticles as extraction sorbent in micro-dispersive solid-phase extraction followed by ultra-high-performance liquid chroma. Anal. Bioanal. Chem. 2018, 410, 2031-2042. [CrossRef]

52. Yang, X.; Qiao, K.; Liu, F.; Wu, X.; Yang, M.; Li, J.; Gao, H.; Zhang, S.; Zhou, W.; Lu, R. Magnetic mixed hemimicelles dispersive solid-phase extraction based on ionic liquid-coated attapulgite/polyaniline-polypyrrole/ $\mathrm{Fe}_{3} \mathrm{O}_{4}$ nanocomposites for determination of acaricides in fruit juice prior to high-performance liquid chromatography-diode array. Talanta 2017, 166, 93-100. [CrossRef]

53. Li, X.; Mei, X.; Xu, L.; Shen, X.; Zhu, W.; Hong, J.; Zhou, X. Development and application of novel clonazepam molecularly imprinted coatings for stir bar sorptive extraction. J. Colloid Interface Sci. 2016, 468, 183-191. [CrossRef] [PubMed]

54. Manoochehri, M.; Asgharinezhad, A.A.; Shekari, N. Synthesis, characterisation and analytical application of Fe3O4@SiO2@polyaminoquinoline magnetic nanocomposite for the extraction and pre-concentration of $\mathrm{Cd}(\mathrm{II})$ and $\mathrm{Pb}(\mathrm{II})$ in food samples. Food Addit. Contam. Part A Chem. Anal. Control Expo. Risk Assess. 2015, 32, 737-747. [CrossRef]

55. Li, N.; Chen, J.; Shi, Y.-P. Magnetic polyethyleneimine functionalized reduced graphene oxide as a novel magnetic solid-phase extraction adsorbent for the determination of polar acidic herbicides in rice. Anal. Chim. Acta 2017, 949, 23-34. [CrossRef] [PubMed]

56. Jalilian, R.; Taheri, A. Synthesis and application of a novel core-shell-shell magnetic ion imprinted polymer as a selective adsorbent of trace amounts of silver ions. e-Polymers 2018, 18, 123-134. [CrossRef]

57. del Alcudia-León, M.C.; Lucena, R.; Cárdenas, S.; Valcárcel, M. Selective extraction of Bactrocera oleae sexual pheromone from olive oil by dispersive magnetic microsolid phase extraction using a molecularly imprinted nanocomposite. J. Chromatogr. A 2016, 1455, 57-64. [CrossRef]

58. Xie, L.; Jiang, R.; Zhu, F.; Liu, H.; Ouyang, G. Application of functionalized magnetic nanoparticles in sample preparation. Anal. Bioanal. Chem. 2014, 406, 377-399. [CrossRef]

59. Moradi Shahrebabak, S.; Saber-Tehrani, M.; Faraji, M.; Shabanian, M.; Aberoomand-Azar, P. Simultaneous magnetic solid phase extraction of acidic and basic pesticides using triazine-based polymeric network modified magnetic nanoparticles/graphene oxide nanocomposite in water and food samples. Microchem. J. 2019, 146, 630-639. [CrossRef]

60. Xu, S.; Luo, Y.; Tan, B. Recent development of hypercrosslinked microporous organic polymers. Macromol. Rapid Commun. 2013, 34, 471-484. [CrossRef]

61. Wang, X.; Feng, T.; Wang, J.; Hao, L.; Wang, C.; Wu, Q.; Wang, Z. Preparation of magnetic porous covalent triazine-based organic polymer for the extraction of carbamates prior to high performance liquid chromatography-mass spectrometric detection. J. Chromatogr. A 2019, 1602, 178-187. [CrossRef]

62. Sharma, R.; Ragavan, K.V.; Thakur, M.S.; Raghavarao, K.S.M.S. Recent advances in nanoparticle based aptasensors for food contaminants. Biosens. Bioelectron. 2015, 74, 612-627. [CrossRef]

63. Seddaoui, N.; Amine, A. A sensitive colorimetric immunoassay based on poly(dopamine) modified magnetic nanoparticles for meat authentication. LWT 2020, 122, 109045. [CrossRef]

64. Guan, H.; Song, Y.; Han, B.; Gong, D.; Zhang, N. Colorimetric detection of cholesterol based on peroxidase mimetic activity of GoldMag nanocomposites. Spectrochim. Acta Part. A Mol. Biomol. Spectrosc. 2020, 241, 118675. [CrossRef] [PubMed]

65. Li, H.; Ahmad, W.; Rong, Y.; Chen, Q.; Zuo, M.; Ouyang, Q.; Guo, Z. Designing an aptamer based magnetic and upconversion nanoparticles conjugated fluorescence sensor for screening Escherichia coli in food. Food Control. 2020, 107, 106761. [CrossRef]

66. Wang, C.; Xiao, R.; Wang, S.; Yang, X.; Bai, Z.; Li, X.; Rong, Z.; Shen, B.; Wang, S. Magnetic quantum dot based lateral flow assay biosensor for multiplex and sensitive detection of protein toxins in food samples. Biosens. Bioelectron. 2019, 146, 111754. [CrossRef] [PubMed] 
67. Jie, M.; Yu, S.; Yu, F.; Liu, L.; He, L.; Li, Y.; Zhang, H.; Qu, L.; de Harrington, P.B.; Wu, Y. An ultrasensitive chemiluminescence immunoassay for fumonisin B1 detection in cereals based on gold-coated magnetic nanoparticles. J. Sci. Food Agric. 2018, 98, 3384-3390. [CrossRef]

68. Hao, L.; Gu, H.; Duan, N.; Wu, S.; Ma, X.; Xia, Y.; Wang, H.; Wang, Z. A chemiluminescent aptasensor based on rolling circle amplification and $\mathrm{Co} 2+/ \mathrm{N}-($ aminobutyl)-N-(ethylisoluminol) functional flowerlike gold nanoparticles for Salmonella typhimurium detection. Talanta 2017, 164, 275-282. [CrossRef]

69. Jia, Y.; Peng, Y.; Bai, J.; Zhang, X.; Cui, Y.; Ning, B.; Cui, J.; Gao, Z. Magnetic nanoparticle enhanced surface plasmon resonance sensor for estradiol analysis. Sens. Actuators B Chem. 2018, 254, 629-635. [CrossRef]

70. Liu, X.; Hu, Y.; Zheng, S.; Liu, Y.; He, Z.; Luo, F. Surface plasmon resonance immunosensor for fast, highly sensitive, and in situ detection of the magnetic nanoparticles-enriched Salmonella enteritidis. Sens. Actuators B Chem. 2016, 230, 191-198. [CrossRef]

71. Chattopadhyay, S.; Sabharwal, P.K.; Jain, S.; Kaur, A.; Singh, H. Functionalized polymeric magnetic nanoparticle assisted SERS immunosensor for the sensitive detection of S. typhimurium. Anal. Chim. Acta 2019, 1067, 98-106. [CrossRef]

72. Yang, M.; Liu, G.; Mehedi, H.M.; Ouyang, Q.; Chen, Q. A universal SERS aptasensor based on DTNB labeled GNTs/Ag core-shell nanotriangle and CS-Fe3O4 magnetic-bead trace detection of Aflatoxin B1. Anal. Chim. Acta 2017, 986, 122-130. [CrossRef]

73. Angulo-Ibáñez, A.; Eletxigerra, U.; Lasheras, X.; Campuzano, S.; Merino, S. Electrochemical tropomyosin allergen immunosensor for complex food matrix analysis. Anal. Chim. Acta 2019, 1079, 94-102. [CrossRef] [PubMed]

74. Plácido, A.; Pereira, C.; Guedes, A.; Barroso, M.F.; Miranda-Castro, R.; de-los-Santos-Álvarez, N.; Delerue-Matos, C. Electrochemical genoassays on gold-coated magnetic nanoparticles to quantify genetically modified organisms (GMOs) in food and feed as GMO percentage. Biosens. Bioelectron. 2018, 110, 147-154. [CrossRef] [PubMed]

75. Waifalkar, P.P.; Chougale, A.D.; Kollu, P.; Patil, P.S.; Patil, P.B. Magnetic nanoparticle decorated graphene based electrochemical nanobiosensor for $\mathrm{H} 2 \mathrm{O} 2$ sensing using HRP. Colloids Surf. B Biointerfaces 2018, 167, 425-431. [CrossRef] [PubMed]

76. Liu, X.; Zheng, S.; Hu, Y.; Li, Z.; Luo, F.; He, Z. Electrochemical Immunosensor Based on the Chitosan-Magnetic Nanoparticles for Detection of Tetracycline. Food Anal. Methods 2016, 9, 2972-2978. [CrossRef]

77. Han, Q.; Shen, X.; Zhu, W.; Zhu, C.; Zhou, X.; Jiang, H. Magnetic sensing film based on Fe3O4@Au-GSH molecularly imprinted polymers for the electrochemical detection of estradiol. Biosens. Bioelectron. 2016, 79, 180-186. [CrossRef]

78. Zhao, J.; Guo, W.; Pei, M.; Ding, F. GR-Fe3O4NPs and PEDOT-AuNPs composite based electrochemical aptasensor for the sensitive detection of penicillin. Anal. Methods 2016, 8, 4391-4397. [CrossRef]

79. Chen, M.; Gan, N.; Zhang, H.; Yan, Z.; Li, T.; Chen, Y.; Xu, Q.; Jiang, Q. Electrochemical simultaneous assay of chloramphenicol and PCB72 using magnetic and aptamer-modified quantum dot-encoded dendritic nanotracers for signal amplification. Microchim. Acta 2016, 183, 1099-1106. [CrossRef]

80. Wang, H.; Wang, L.; Hu, Q.; Wang, R.; Li, Y.; Kidd, M. Rapid and sensitive detection of campylobacter jejuni in poultry products using a nanoparticle-based piezoelectric immunosensor integrated with magnetic immunoseparation. J. Food Prot. 2018, 81, 1321-1330. [CrossRef]

81. Chen, S.; Pan, D.; Gan, N.; Wang, D.; Zhu, Y.; Li, T.; Cao, Y.; Hu, F.; Jiang, S. A QCM immunosensor to rapidly detect ractopamine using bio-polymer conjugate and magnetic $\beta$-cyclodextrins. Sens. ActuatorsB Chem. 2015, 211, 523-530. [CrossRef]

82. Xianyu, Y.; Dong, Y.; Wang, Z.; Xu, Z.; Huang, R.; Chen, Y. Broad-Range Magnetic Relaxation Switching Bioassays Using Click Chemistry-Mediated Assembly of Polystyrene Beads and Magnetic Nanoparticles. ACS Sens. 2019, 4, 1942-1949. [CrossRef]

83. Zou, D.; Jin, L.; Wu, B.; Hu, L.; Chen, X.; Huang, G.; Zhang, J. Rapid detection of Salmonella in milk by biofunctionalised magnetic nanoparticle cluster sensor based on nuclear magnetic resonance. Int. Dairy J. 2019, 91, 82-88. [CrossRef]

84. Kaittanis, C.; Naser, S.A.; Perez, J.M. One-step, nanoparticle-mediated bacterial detection with magnetic relaxation. Nano Lett. 2007, 7, 380-383. [CrossRef] [PubMed]

85. Eissa, S.; Zourob, M. A dual electrochemical/colorimetric magnetic nanoparticle/peptide-based platform for the detection of Staphylococcus aureus. Analyst 2020, 145, 4606-4614. [CrossRef] [PubMed] 
86. Lin, Y.; Zhou, Q.; Tang, D.; Niessner, R.; Knopp, D. Signal-On Photoelectrochemical Immunoassay for Aflatoxin B1 Based on Enzymatic Product-Etching MnO2 Nanosheets for Dissociation of Carbon Dots. Anal. Chem. 2017, 89, 5637-5645. [CrossRef] [PubMed]

87. Poo-arporn, Y.; Pakapongpan, S.; Chanlek, N.; Poo-arporn, R.P. The development of disposable electrochemical sensor based on $\mathrm{Fe}_{3} \mathrm{O}_{4}$-doped reduced graphene oxide modified magnetic screen-printed electrode for ractopamine determination in pork sample. Sens. Actuators B Chem. 2019, 284, 164-171. [CrossRef]

88. Wilson, D.; Materón, E.M.; Ibáñez-Redín, G.; Faria, R.C.; Correa, D.S.; Oliveira, O.N. Electrical detection of pathogenic bacteria in food samples using information visualization methods with a sensor based on magnetic nanoparticles functionalized with antimicrobial peptides. Talanta 2019, 194, 611-618. [CrossRef]

89. Bettazzi, F.; Natale, A.R.; Torres, E.; Palchetti, I. Glyphosate determination by coupling an immuno-magnetic assay with electrochemical sensors. Sensors 2018, 18, 2965. [CrossRef]

90. Marinho Rodrigues, N.F.; Yotsumoto Neto, S.; de Silva Luz, R.C.; Santos Damos, F.; Yamanaka, H. Ultrasensitive determination of malathion using acetylcholinesterase immobilized on chitosan-functionalized magnetic iron nanoparticles. Biosensors 2018, 8, 16. [CrossRef]

91. Bettazzi, F.; Martellini, T.; Shelver, W.L.; Cincinelli, A.; Lanciotti, E.; Palchetti, I. Development of an Electrochemical Immunoassay for the Detection of Polybrominated Diphenyl Ethers (PBDEs). Electroanalysis 2016, 28, 1817-1823. [CrossRef]

92. Zhang, X.; Wang, Z.; Xie, H.; Sun, R.; Cao, T.; Paudyal, N.; Fang, W.; Song, H. Development of a magnetic nanoparticles-based screen-printed electrodes (MNPs-SPEs) biosensor for the quantification of ochratoxin A in cereal and feed samples. Toxins 2018, 10, 317. [CrossRef]

93. Moyano, A.; Salvador, M.; Martínez-García, J.C.; Socoliuc, V.; Vékás, L.; Peddis, D.; Alvarez, M.A.; Fernández, M.; Rivas, M.; Blanco-López, M.C. Magnetic immunochromatographic test for histamine detection in wine. Anal. Bioanal. Chem. 2019, 411, 6615-6624. [CrossRef] [PubMed]

94. Yao, X.; Wang, Z.; Dou, L.; Zhao, B.; He, Y.; Wang, J.; Sun, J.; Li, T.; Zhang, D. An innovative immunochromatography assay for highly sensitive detection of 17B-estradiol based on an indirect probe strategy. Sens. Actuators B Chem. 2019, 289, 48-55. [CrossRef]

95. Wu, Z.; He, D.; Xu, E.; Jiao, A.; Chughtai, M.F.J.; Jin, Z. Rapid detection of $\beta$-conglutin with a novel lateral flow aptasensor assisted by immunomagnetic enrichment and enzyme signal amplification. Food Chem. 2018, 269, 375-379. [CrossRef] [PubMed]

96. Orlov, A.V.; Znoyko, S.L.; Cherkasov, V.R.; Nikitin, M.P.; Nikitin, P.I. Multiplex Biosensing Based on Highly Sensitive Magnetic Nanolabel Quantification: Rapid Detection of Botulinum Neurotoxins A, B, and e in Liquids. Anal. Chem. 2016, 88, 10419-10426. [CrossRef] [PubMed]

97. Cai, G.; Zheng, L.; Liao, M.; Li, Y.; Wang, M.; Liu, N.; Lin, J. A microfluidic immunosensor for visual detection of foodborne bacteria using immunomagnetic separation, enzymatic catalysis and distance indication. Microchim. Acta 2019, 186, 757. [CrossRef] [PubMed]

98. Man, Y.; Li, A.; Li, B.; Liu, J.; Pan, L. A microfluidic colorimetric immunoassay for sensitive detection of altenariol monomethyl ether by UV spectroscopy and smart phone imaging. Anal. Chim. Acta 2019, 1092, 75-84. [CrossRef] [PubMed]

99. Duarte, C.; Costa, T.; Carneiro, C.; Soares, R.; Jitariu, A.; Cardoso, S.; Piedade, M.; Bexiga, R.; Freitas, P. Semi-quantitative method for streptococci magnetic detection in raw milk. Biosensors 2016, 6, 19. [CrossRef]

100. Park, Y.M.; Kim, C.H.; Lee, S.J.; Lee, M.K. Multifunctional hand-held sensor using electronic components embedded in smartphones for quick PCR screening. Biosens. Bioelectron. 2019, 141, 111415. [CrossRef]

101. Guo, R.; Wang, S.; Huang, F.; Chen, Q.; Li, Y.; Liao, M.; Lin, J. Rapid detection of Salmonella Typhimurium using magnetic nanoparticle immunoseparation, nanocluster signal amplification and smartphone image analysis. Sens. Actuators B Chem. 2019, 284, 134-139. [CrossRef]

102. Farooq, U.; Yang, Q.; Ullah, M.W.; Wang, S. Bacterial biosensing: Recent advances in phage-based bioassays and biosensors. Biosens. Bioelectron. 2018, 118, 204-216. [CrossRef] 
103. Cristea, C.; Tertis, M.; Galatus, R. Magnetic nanoparticles for antibiotics detection. Nanomaterials 2017, 7, 119. [CrossRef] [PubMed]

104. Squissato, A.L.; Munoz, R.A.A.; Banks, C.E.; Richter, E.M. An Overview of Recent Electroanalytical Applications Utilizing Screen-Printed Electrodes Within Flow Systems. ChemElectroChem 2020, 7, 2211-2221. [CrossRef] 